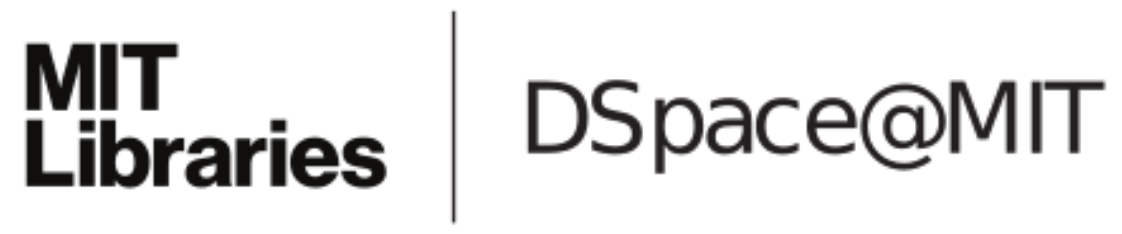

\author{
MIT Open Access Articles
}

\section{Impact of Potential Large-Scale Irrigation on the West African Monsoon and Its Dependence on Location of Irrigated Area}

The MIT Faculty has made this article openly available. Please share how this access benefits you. Your story matters.

Citation: Im, Eun-Soon, Marc P. Marcella, and Elfatih A. B. Eltahir. “Impact of Potential LargeScale Irrigation on the West African Monsoon and Its Dependence on Location of Irrigated Area." J. Climate 27, no. 3 (February 2014): 994-1009. (C) 2014 American Meteorological Society

As Published: http://dx.doi.org/10.1175/jcli-d-13-00290.1

Publisher: American Meteorological Society

Persistent URL: http://hdl.handle.net/1721.1/90307

Version: Final published version: final published article, as it appeared in a journal, conference proceedings, or other formally published context

Terms of Use: Article is made available in accordance with the publisher's policy and may be subject to US copyright law. Please refer to the publisher's site for terms of use. 


\title{
Impact of Potential Large-Scale Irrigation on the West African Monsoon and Its Dependence on Location of Irrigated Area
}

\author{
EUN-SOON IM \\ Center for Environmental Sensing and Modeling, Singapore-Massachusetts Institute of Technology Alliance for \\ Research and Technology, Singapore \\ Marc P. Marcella and Elfatih A. B. Eltahir \\ Ralph M. Parsons Laboratory, Massachusetts Institute of Technology, Cambridge, Massachusetts
}

(Manuscript received 21 May 2013, in final form 29 August 2013)

\begin{abstract}
This study investigates the impact of potential large-scale irrigation on the West African monsoon using the Massachusetts Institute of Technology regional climate model (MRCM). A new irrigation module is implemented to assess the impact of location and scheduling of irrigation on rainfall distribution over West Africa. A control simulation (without irrigation) and eight sensitivity experiments (with irrigation) are performed and compared to discern the effects of irrigation location and scheduling. It is found that the irrigation effect on soil moisture could force significant changes in spatial distribution and magnitude of rainfall, depending on the latitudinal location of irrigation. In general, the large irrigation-induced surface cooling owing to anomalously wet soil tends to suppress moist convection and rainfall, which in turn induces local subsidence and low-level anticyclonic circulation. These local effects are dominated by a consistent reduction of local rainfall over the irrigated land, irrespective of its location. However, the remote response of rainfall distribution to irrigation exhibits a significant sensitivity to the latitudinal position of irrigation and the intraseasonal variation of supplied irrigation water. The low-level northeasterly airflow associated with an anticyclonic circulation centered over the irrigation area, induced at optimal location and timing, would enhance the extent of low-level convergence areas through interaction with the prevailing monsoon flow, leading to a significant increase in rainfall. As the location of the irrigation area is moved from the coast northward, the regional rainfall change exhibits a significant decrease first, then increases gradually to a maximum corresponding to irrigation centered around $20^{\circ} \mathrm{N}$, before it declines again.
\end{abstract}

\section{Introduction}

West Africa and its inhabitants are particularly vulnerable to droughts owing to highly variable rainfall and rapid population growth. Given that the West Africans are largely dependent on the availability of their water resources, the risks posed by the potential impact of climate variability (e.g., climate extremes such as floods and droughts) could lead to conflicts and environmentally induced migration (UNEP 2011).

Irrigation supplies water to assure sufficient soil wetness for plant growth; in terms of the meteorological

Corresponding author address: Dr. Eun-Soon Im, SingaporeMIT Alliance for Research and Technology Center for Environmental Sensing and Modeling, 1 CREATE Way, 09-03 CREATE Tower, 138602 Singapore.

E-mail: eunsoon@smart.mit.edu conditions, this practice results in anomalous soil moisture conditions. Several studies have reported that irrigation may have important effects on regional climate by altering the surface energy partitioning as well as water cycle through modulation of heat, moisture, and momentum exchanges between the surface and atmosphere (Pielke et al. 2002; Ozdogan et al. 2010; Kueppers et al. 2007; Lo and Famiglietti 2013). The first-order effect induced by additional moisture appears to be surface cooling and increased evapotranspiration (Segal et al. 1998; Cook et al. 2011), leading to the change of local climate of the irrigated area. Here we test the hypothesis that changes in surface wetness associated with irrigation can also modify the circulation pattern, which may remotely control the rainfall over regions far from irrigated fields. Hence, we seek to quantify and understand the irrigation-induced changes in both local and remote rainfall. 
Until recently, most of the studies on the impact of irrigation have been based upon modeling and observational analyses focused over North America (Kueppers et al. 2007; Lo and Famiglietti 2013; Diffenbaugh 2009; Mohmood and Hubbard 2002; Segal et al. 1998; Adegoke et al. 2003; Moore and Rojstaczer 2001; Sorooshian et al. 2011, 2012; Kustu et al. 2010, 2011; DeAngelis et al. 2010) due to the data rich status of this region (Lobell et al. 2009). However, despite the relevance of potential irrigation to West Africa, we are unaware of any studies over this region addressing this topic explicitly from the meteorological perspective. Furthermore, West Africa is considered a "hot spot" for soil moisture-rainfall coupling (Koster et al. 2004; Wang et al. 2007); therefore, it is reasonable to expect that anomalous soil moisture induced by irrigation can have a significant impact on the West African monsoon (WAM).

In this study, we attempt to explore the impact of the location and scheduling of irrigation on the West African monsoon using a state-of-the-art regional climate model (Im et al. 2013, manuscript submitted to J. Climate) that includes the Integrated Biosphere Simulator (IBIS) land surface scheme and a new irrigation module (Marcella and Eltahir 2014). This is a theoretical study that seeks better understanding of the climatic impact of irrigation. Although we consider large irrigated areas on the order of approximately $4 \times 10 \mathrm{~km}^{2}$ (e.g., lengths scale of $600-700 \mathrm{~km}$ ), we recognize that such a scale of land conversion and associated water use are too large for realistic development scenarios in the region. Various sensitivity experiments designed to isolate the effect of the irrigation location and scheduling are performed and analyzed. The specific objectives of this study are 1) to find out if there are optimal location and timing for irrigation that maximizes rainfall increase over the region and 2) to investigate the physical mechanisms shaping the changes of rainfall due to irrigation.

\section{Model configuration and experimental design}

\section{a. The MIT regional climate model}

In this study, the Massachusetts Institute of Technology (MIT) regional climate model (MRCM) is used to examine the effects of irrigation on the West African monsoon system. Based on the regional climate model, version 3 (RegCM3) (Pal et al. 2007), MRCM maintains much of the structure of that RCM but with several improvements, including coupling to the IBIS land surface scheme (Winter et al. 2009), a new bare soil albedo assignment method (Marcella 2012), new convective cloud and convective rainfall autoconversion schemes (Gianotti and Eltahir 2014a,b), and modified boundary layer height and boundary layer cloud schemes (Gianotti 2012). A detailed model description and validation of the MRCM performance in simulating the WAM can be found in Im et al. (2013, manuscript submitted to J. Climate). The irrigation scheme of Marcella and Eltahir (2014) is used to represent an irrigated cropland in the IBIS biome.

The main features of the irrigation scheme are described in the following. Recalling the water balance equation for soil moisture in the irrigated area,

$$
\Delta S=P-R-\mathrm{ET}+I-D .
$$

Essentially, the change in storage of the soil moisture of a layer $(\Delta S)$ is calculated based on the amount of precipitation $(P)$ that falls, reducing water that runs off $(R)$ and that drains into deeper layers $(D)$ and reducing water that evaporates from the ground/canopy or transpires through plants (ET). Therefore, when specifying a set value for the root-zone soil moisture, in terms of its relative saturation $s$ (volumetric soil moisture divided by porosity), one can use the above equation to calculate the amount of water needed $(I)$ to irrigate a region and increase the soil moisture content up to any prescribed soil moisture level. This prescribed soil moisture value, $s$, the relative soil saturation, is as assumed to be the relative field capacity, which is the field capacity $\left(\theta_{\mathrm{fc}}\right)$ divided by the porosity $(\varphi)$ of a soil layer. Both $\theta_{\mathrm{fc}}$ and $\varphi$ for the four layers that constitute the root zone (the top one meter of soil) are specified based on the observational soil texture input datasets of IBIS. From these four layers, a weighted average (based on the depth of each of the four layers) rootzone relative field capacity is computed. For the purpose of specifying the initial conditions of the soil, an offline version of IBIS was forced by prescribed atmospheric data, and the resulting equilibrium conditions (soil moisture and soil temperature for each soil layer) were used for the initialization of soil conditions. For all time steps in which irrigation is active, an irrigated grid cell soil moisture is forced to relative field capacity by adding water to the root zone. Further details are described in Marcella (2012) and Marcella and Eltahir (2014).

The initial and boundary conditions used by the MRCM are specified according to the Interim European Centre for Medium-Range Weather Forecasts (ECMWF) Re-Analysis (ERA-Interim) with a resolution of $1.5^{\circ} \times 1.5^{\circ}$ at a 6 -h interval, which is the thirdgeneration ECMWF reanalysis project (Uppala et al. 2008). The simulations span 20 years from January 1989 to December 2008. Although additional spinup time is not assigned, this should not introduce a significant 


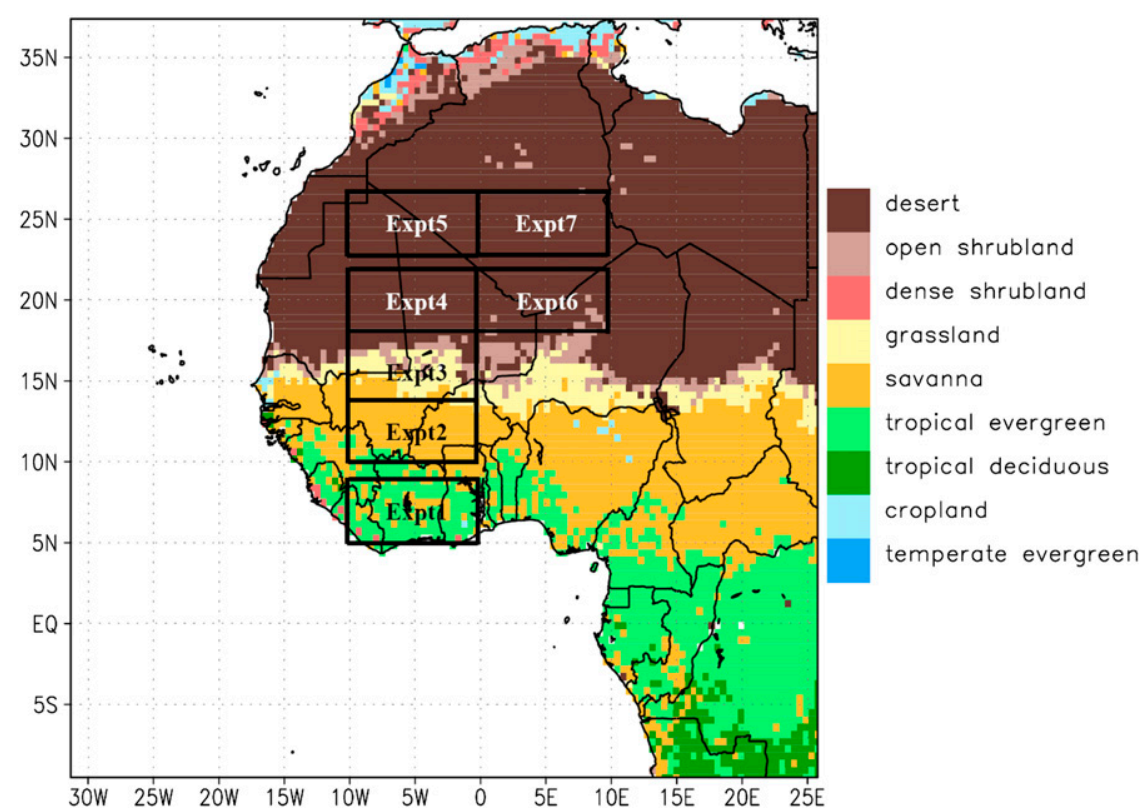

FIG. 1. Model domain and land-use distribution in the control and sensitivity experiments. The rectangles indicate the irrigated area, and inside numbers correspond to the experiments denoted in Table 1.

problem because of the way initial conditions are specified. The sea surface temperatures (SSTs) are prescribed by the National Oceanic and Atmospheric Administration optimum interpolation (OI) SST dataset with a horizontal and temporal resolution of $1^{\circ} \times$ $1^{\circ}$ and weekly interval.

\section{b. Experimental design}

Figure 1 shows the model domain and land use distribution in the control (CONT) and sensitivity experiments. The domain covers most of West Africa and the Atlantic Ocean centered at $15^{\circ} \mathrm{N}, 3^{\circ} \mathrm{W}$ with $50-\mathrm{km}$ horizontal resolution (130 grid points zonally and 114 grid points meridionally). The seven boxes $(\operatorname{EXP} n, n=1, \ldots, 7$; hereafter Expt $n)$ indicate the irrigated area with a different location for each sensitivity experiment.

Table 1 summarizes all experiments performed in this study. The location of irrigation in Expt1 through Expt5 is progressively shifted northward from the coast to the Sahara Desert to quantify the sensitivity to the latitudinal location of irrigation. In contrast, Expt6 and Expt7 shift the irrigation eastward; thus, comparisons between Expt 4 and Expt6 or between Expt5 and Expt7 elucidate the sensitivity to the longitudinal location of irrigation. Given that in the standard experiments (Expt1 to Expt7) irrigation forces soil moisture to be kept saturated at every time step from May to September (MJJAS), unrealistic amounts of water may be required to satisfy that constraint. Therefore, we perform an additional experiment to consider the effect of scheduling on Expt4, named Expt4_S1W. In this case, water is only applied in the first week of June, July, and August. Basically, the water amount for irrigation is determined by the specific conditions (e.g., rainfall amounts and soil properties) of a given location (see section 3c); however, scheduling techniques to intermittently supply irrigation water can also control the water amount. Comparing irrigation water between Expt4 and Expt4_S1W clearly demonstrates the efficiency of a scheduling technique in terms of water use. This technique mimics the irrigation practices

TABLE 1 . Summary of the control and sensitivity experiments with different location, extent, and scheduling for irrigation.

\begin{tabular}{lllr}
\hline \hline & \multicolumn{1}{c}{$\begin{array}{c}\text { Irrigation } \\
\text { area } \\
\text { (lat, lon) }\end{array}$} & $\begin{array}{c}\text { Irrigation } \\
\text { period }\end{array}$ & $\begin{array}{c}\text { Irrigated } \\
\text { water } \\
\left(\mathrm{km}^{3} \mathrm{yr}^{-1}\right)\end{array}$ \\
\hline CONT & No irrigation & No irrigation & \\
Expt1 & $5^{\circ}-9^{\circ} \mathrm{N}, 10^{\circ} \mathrm{W}-0^{\circ}$ & MJJAS & 74 \\
Expt2 & $10^{\circ}-14^{\circ} \mathrm{N}, 10^{\circ} \mathrm{W}-0^{\circ}$ & MJJAS & 152 \\
Expt3 & $14^{\circ}-18^{\circ} \mathrm{N}, 10^{\circ} \mathrm{W}-0^{\circ}$ & MJJAS & 230 \\
Expt4 & $18^{\circ}-22^{\circ} \mathrm{N}, 10^{\circ} \mathrm{W}-0^{\circ}$ & MJJAS & 271 \\
Expt5 & $23^{\circ}-27^{\circ} \mathrm{N}, 10^{\circ} \mathrm{W}-0^{\circ}$ & MJJAS & 292 \\
Expt6 & $18^{\circ}-22^{\circ} \mathrm{N}, 0-10^{\circ} \mathrm{E}$ & MJJAS & 307 \\
Expt7 & $23^{\circ}-27^{\circ} \mathrm{N}, 0-10^{\circ} \mathrm{E}$ & MJJAS & 286 \\
Expt4_S1W & $18^{\circ}-22^{\circ} \mathrm{N}, 10^{\circ} \mathrm{W}-0^{\circ}$ & First week of & 92 \\
& & Jun-Aug & \\
\hline
\end{tabular}


(a) CRU

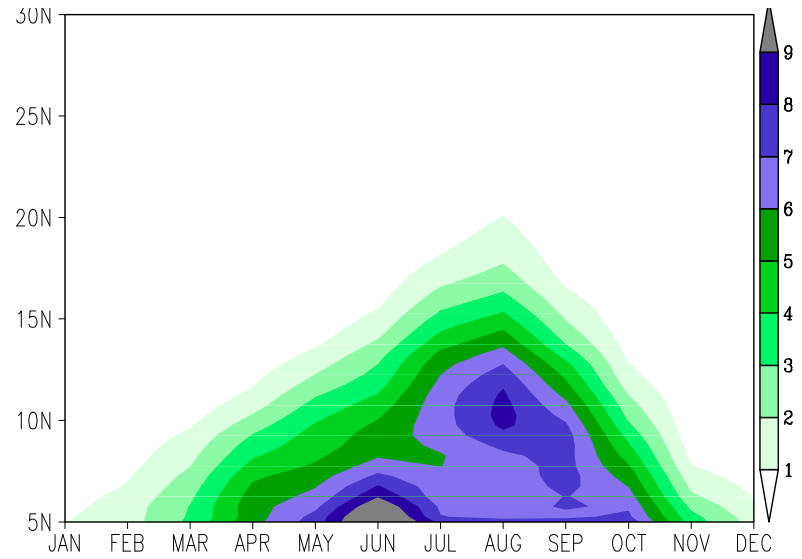

(b) MRCM

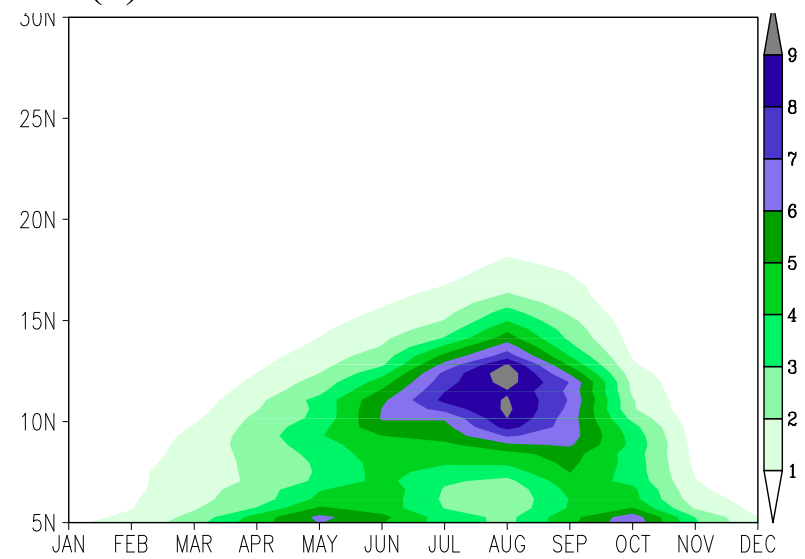

FIG. 2. Latitude-time cross section of monthly mean rainfall $\left(\mathrm{mm} \mathrm{day}^{-1}\right)$ averaged from $10^{\circ} \mathrm{W}$ to $10^{\circ} \mathrm{E}$ from the CRU observation and the MRCM CONT simulation averaged over the period 1989-2008.

assumed in other studies (Marcella and Eltahir 2012; Sorooshian et al. 2012).

\section{Results}

Since the performance of MRCM over West Africa (i.e., CONT) is comprehensively evaluated against various observations in Im et al. (2013, manuscript submitted to J. Climate), in this paper we only present one representative result. Generally, the MRCM exhibits the reasonable performance with respect to the spatial distribution and seasonal variation of rainfall as well as the dynamics of WAM. Figure 2 shows the latitude-time cross section of the zonally averaged rainfall along $10^{\circ} \mathrm{W}-10^{\circ} \mathrm{E}$ for the Climatic Research Unit (CRU) observation and the MRCM CONT simulation. The rainfall amount of MRCM agrees reasonably well with observation during August with some small overestimation, although it underestimates the rainfall along the Guinean coast during May. This performance of MRCM is comparable to various state-of-the-art regional climate models participating in the Coordinated Regional Downscaling Experiment in Africa (CORDEX-Africa) reported by Nikulin et al. (2012).

Based on the reliability of the CONT simulation, we present results on the analysis of the effect of irrigation location and scheduling. First, in sections $3 a$ to $3 \mathrm{c}$ we examine the effect of irrigation location with an emphasis on the local and remote responses of rainfall distribution. We then present in section 3d the results of Expt4_S1W to illustrate the effect of irrigation scheduling.

\section{a. The effect of irrigation location on rainfall change}

First, analysis is completed focusing on changes to rainfall distribution as the location of irrigation is moved across West Africa. Figure 3 presents the difference between the CONT and Expt1 through Expt7 daily rainfall rates for the period May through September. The most consistent pattern appearing in all simulations is a decrease in rainfall over the irrigated area itself. The magnitude of the rainfall decrease seems to be proportional to the rainfall climatology of each irrigated area. Normalized differences of rainfall changes show a similar relative magnitude of decrease over each irrigated region (not shown). This response to anomalous wet soil moisture is somewhat different than those of Pal and Eltahir (2001, 2003), Adegoke et al. (2003), Moore and Rojstaczer (2001), and Segal et al. (1998), which present a positive feedback between soil moisture and rainfall at the local scale. An increase in soil moisture enhances evapotranspiration, resulting in a higher moisture flux and moist static energy (MSE) in the planetary boundary layer (PBL). As a result, convective activity is predicted to increase over a region with higher soil moisture conditions. Our experiments also show the increase of MSE at low levels over the irrigated area (Table 2). However, in these experiments, strong cooling simultaneously occurs with moistening of the lower atmosphere. This surface cooling impacts the process of convection triggering (see section $3 \mathrm{~b}$ ). In these simulations, surface cooling overwhelms other processes and convection is triggered less often.

Considering the impact of irrigation on the surface energy balance, Table 2 provides changes of the major components of the surface energy budget averaged over the irrigated area. All experiments show an increase of net longwave radiation because lower temperature reduces upward longwave radiation and additional water vapor increases downward longwave radiation. Unlike the consistent pattern of the change in net longwave radiation, the change of absorbed shortwave radiation 
(a) Expt1-CONT

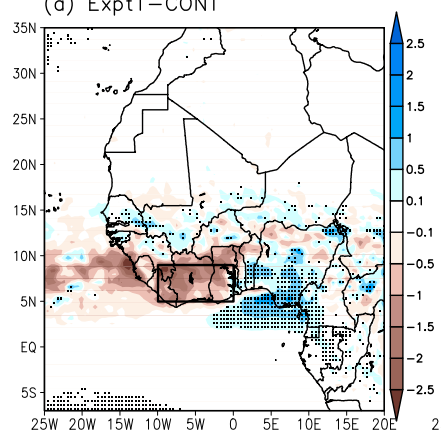

(b) Expt2-CONT

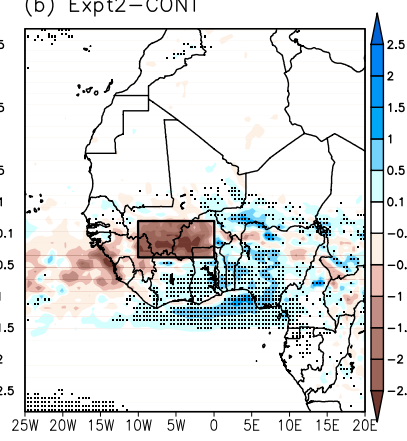

(c) Expt3-CONT

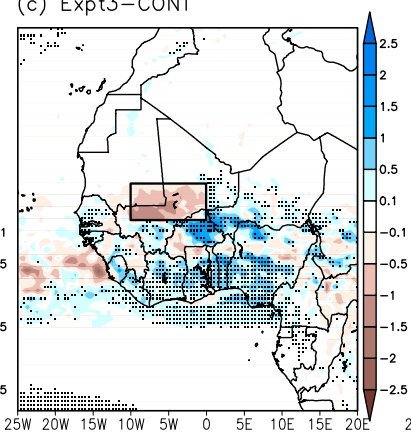

(d) Expt4-CONT

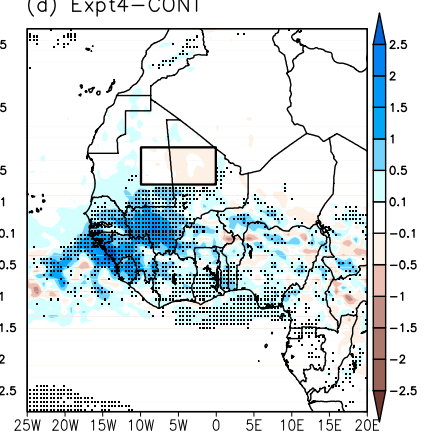

(e) Expt5-CONT

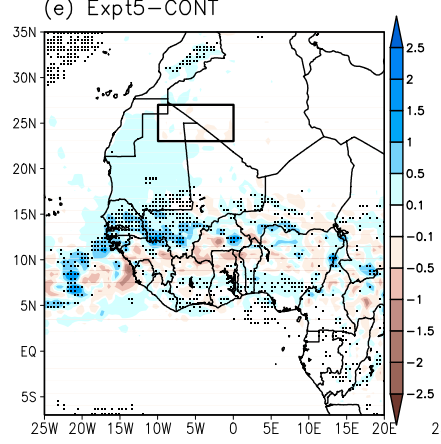

(f) Expt6-CONT

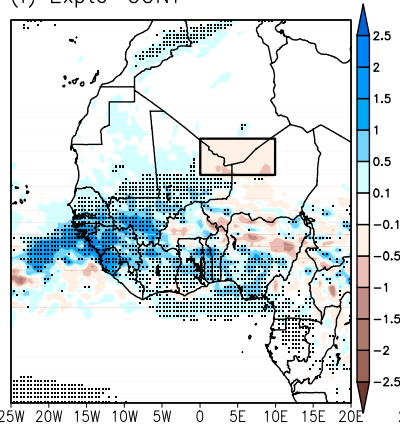

(g) Expt7-CONT

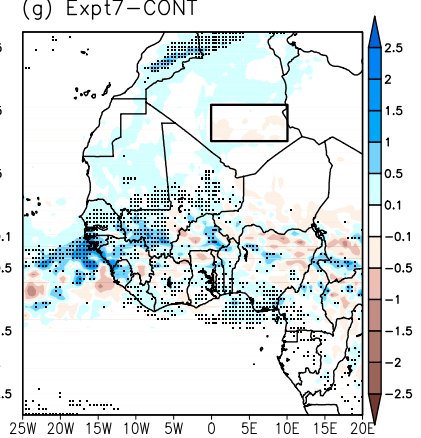

FIG. 3. Spatial distribution of rainfall difference $\left(\mathrm{mm} \mathrm{day}^{-1}\right)$ between irrigation sensitivity (Expt1-Expt7) and CONT experiments averaged over May to September. Superimposed dots indicate the areas where the fraction of the year with rainfall increase is more than 0.6. The region where the CONT rainfall averaged over May to September is less than $50 \mathrm{~mm}$ is masked out of this figure. The black line rectangle indicates the irrigated area for each sensitivity experiment.

shows a regional dependence, partially because of the difference in the albedo of different land cover types assumed in different regions used for CONT. Therefore, the resulting net radiation increases by about $30-75 \mathrm{~W} \mathrm{~m}^{-2}$, except for Exp1 and Expt2. Enhanced soil wetness also changes the partitioning of surface heat fluxes. The sensible heat flux decreases in the range of $15-70 \mathrm{~W} \mathrm{~m}^{-2}$. As expected, the latent heat flux largely increases owing to irrigation, especially as the location is moved northward.

Changes in rainfall are simulated not only in and around the irrigated grid cells but across the Sahel and Gulf of Guinea. Interestingly, changes in rainfall appear to be more sensitive to the latitudinal location rather than the longitudinal location of irrigation. A decrease in rainfall is well pronounced in Expt1 but, as the irrigation is shifted northward, rainfall gradually increases and reaches a maximum in Expt4 and then decreases again in Expt5. On the other hand, the longitudinal placement of irrigation appears less important as evident by the relative similarity of the results of Expt4 to Expt6 and of Expt5 to Expt7. These tendencies are clearly demonstrated in the latitudinal distribution of the rainfall, zonally averaged along $15^{\circ} \mathrm{W}-0^{\circ}$ (Fig. 4). The rainfall distribution shows a strong latitudinal dependency, and all simulations produce the peak around $10^{\circ} \mathrm{N}$ with varying magnitudes in response to irrigation location. To clearly see the dependence of rainfall change on latitudinal and longitudinal position of irrigation, we display the results of Expt1-Expt5 and Expt4 Expt7, separately. The differences between the CONT and Expt1 through Expt5 exhibit a pronounced variation (Fig. 4c). In contrast, the comparison of Expt4 (Expt5) to Expt6 (Expt7) reveals similar patterns (Fig. 4d).

In Fig. 3, dots are overlaid on the areas where the fraction of the simulation years with rainfall increase is more than 0.6 (i.e., 13 out of a total of 20 years) to address the consistency of the pattern of rainfall change across the different years. Note that the region where

TABLE 2. Changes of surface energy balance components $\left(\mathrm{W} \mathrm{m}^{-2}\right)$ and moist static energy (MSE) $\left(10^{3} \mathrm{~J} \mathrm{~kg}^{-1}\right)$ at $1000 \mathrm{hPa}$ averaged over irrigated area. Here, SW Abs, Net LW, Net R, SH, and LH denote absorbed shortwave, net longwave, net radiation, sensible heat flux, and latent heat flux, respectively.

\begin{tabular}{lrrrrrrr}
\hline & Expt1 & Expt2 & Expt3 & Expt4 & Expt5 & Expt6 & Expt7 \\
\hline SW Abs & -19.3 & -18.0 & 0.0 & 22.1 & 14.2 & 10.2 & 9.3 \\
Net LW & 5.3 & 10.6 & 29.1 & 51.5 & 59.1 & 55.4 & 58.5 \\
Net R & -14.1 & -7.4 & 29.1 & 73.6 & 73.5 & 65.6 & 67.8 \\
SH & -16.6 & -36.2 & -61.5 & -57.7 & -66.6 & -69.6 & -67.5 \\
LH & 3.2 & 30.0 & 93.3 & 134.6 & 143.3 & 138.6 & 138.5 \\
MSE & 1.4 & 3.7 & 9.7 & 15.7 & 17.2 & 16.0 & 17.5 \\
\hline
\end{tabular}


(a) Rainfall (Expt1-Expt5)

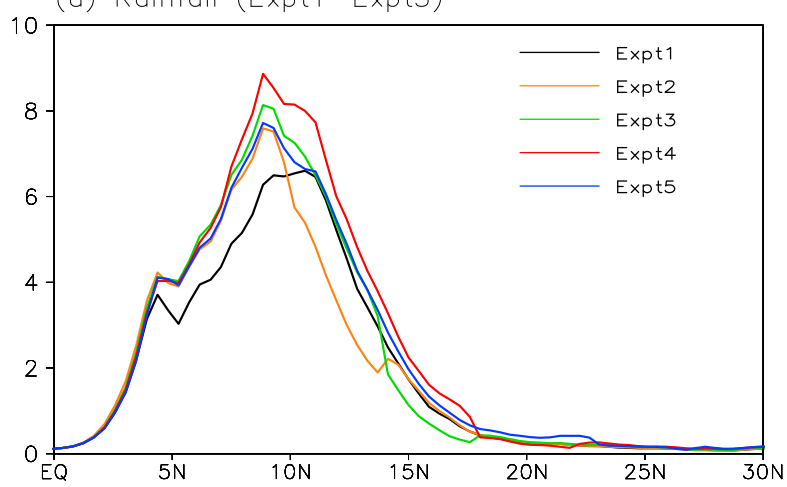

(c) Rainfall Diff. (Expt1-Expt5)

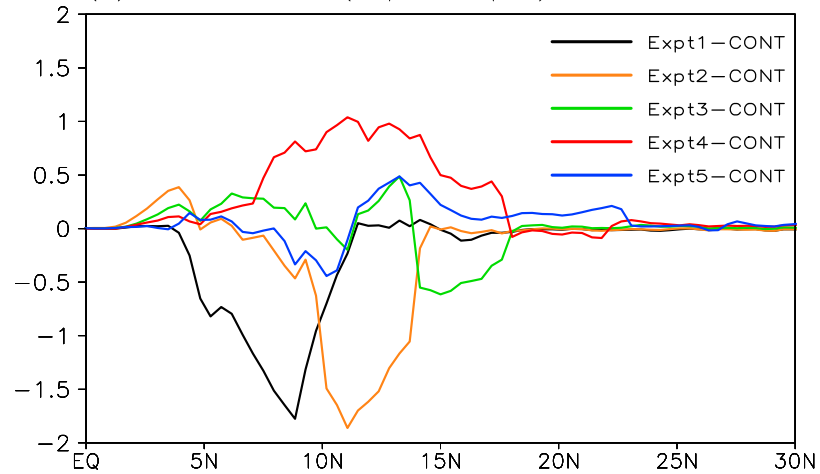

(b) Rainfall (Expt4-Expt7)

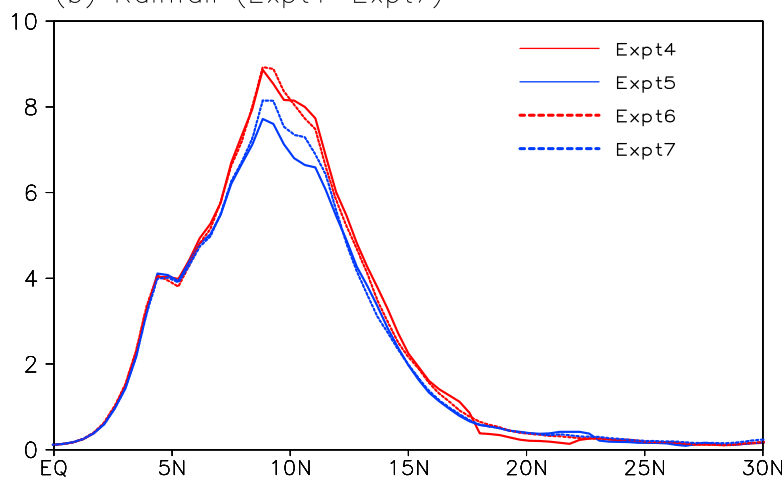

(d) Rainfall Diff. (Expt4-Expt7)

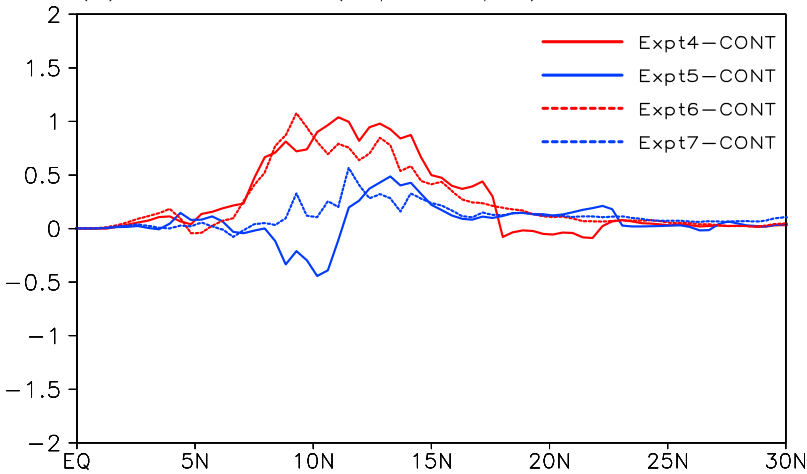

FIG. 4. Latitudinal distribution of (a),(b) the zonally averaged $\left(15^{\circ} \mathrm{W}-0^{\circ}\right)$ rainfall $\left(\mathrm{mm} \mathrm{day}^{-1}\right)$ of irrigation sensitivity experiments and (c),(d) their differences with the CONT experiment during MJJAS. Expt4 (Expt5) denoted by red (blue) line in (a) and (c) is the same as Expt4 (Expt5) in (b) and (d).

the CONT rainfall averaged over May to September is less than $50 \mathrm{~mm}$ is masked out of this figure to avoid the potential inflation due to small rainfall amounts. Large areas with positive changes in rainfall are covered by the dots, especially in Expt 4 and Expt6. This figure implies that rainfall increase is not a random feature of specific year, but a rather consistent pattern in different years.

\section{b. The mechanism of local impact of irrigation on rainfall}

Here analysis is completed in examining the physical processes behind the decrease of rainfall over irrigated areas. To gain insight into the mechanism behind rainfall changes, several variables simulated by Expt 1 and Expt 4 are compared since both simulations show a fairly different behavior, with the opposite sign of rainfall change. Figure 5 presents the diurnal cycle of the surface temperature and PBL height averaged over the irrigated area for each sensitivity experiment. It can be seen that irrigation clearly leads to surface cooling over the corresponding areas. More specifically, surface temperatures drop by more than $8^{\circ} \mathrm{C}$ in the daytime in Expt 4 and the magnitude of cooling is larger than that of Expt1. Lower temperature reduces the sensible heat flux and restricts the PBL height growth. In fact, the change of PBL height seems to follow closely the temperature change. A large reduction of $\mathrm{PBL}$ height is observed in Expt4 during the daytime when the convection activity is maximum.

To explain such a change in association with convection, we investigate the number of days in which convection is triggered with convective rainfall greater than $1.0 \mathrm{~mm} \mathrm{day}^{-1}$ (Fig. 6). This variable can serve as a proxy for the frequency of convective triggering. Over the irrigated region, a significant reduction of days with moist convection is found in both Expt1 and Expt4, irrespective of location.

To uncover the physical mechanism controlling local feedback between irrigated water and convective rainfall, the atmospheric thermodynamic structure is examined further to analyze the process of triggering convection. For example, Fig. 7 shows the frequency distribution of convective inhibition (CIN), convective available potential energy (CAPE), and equivalent potential temperature $\left(\theta_{e}\right)$ averaged over the Expt4 irrigated area from CONT and Expt 4 output at 1200 UTC 

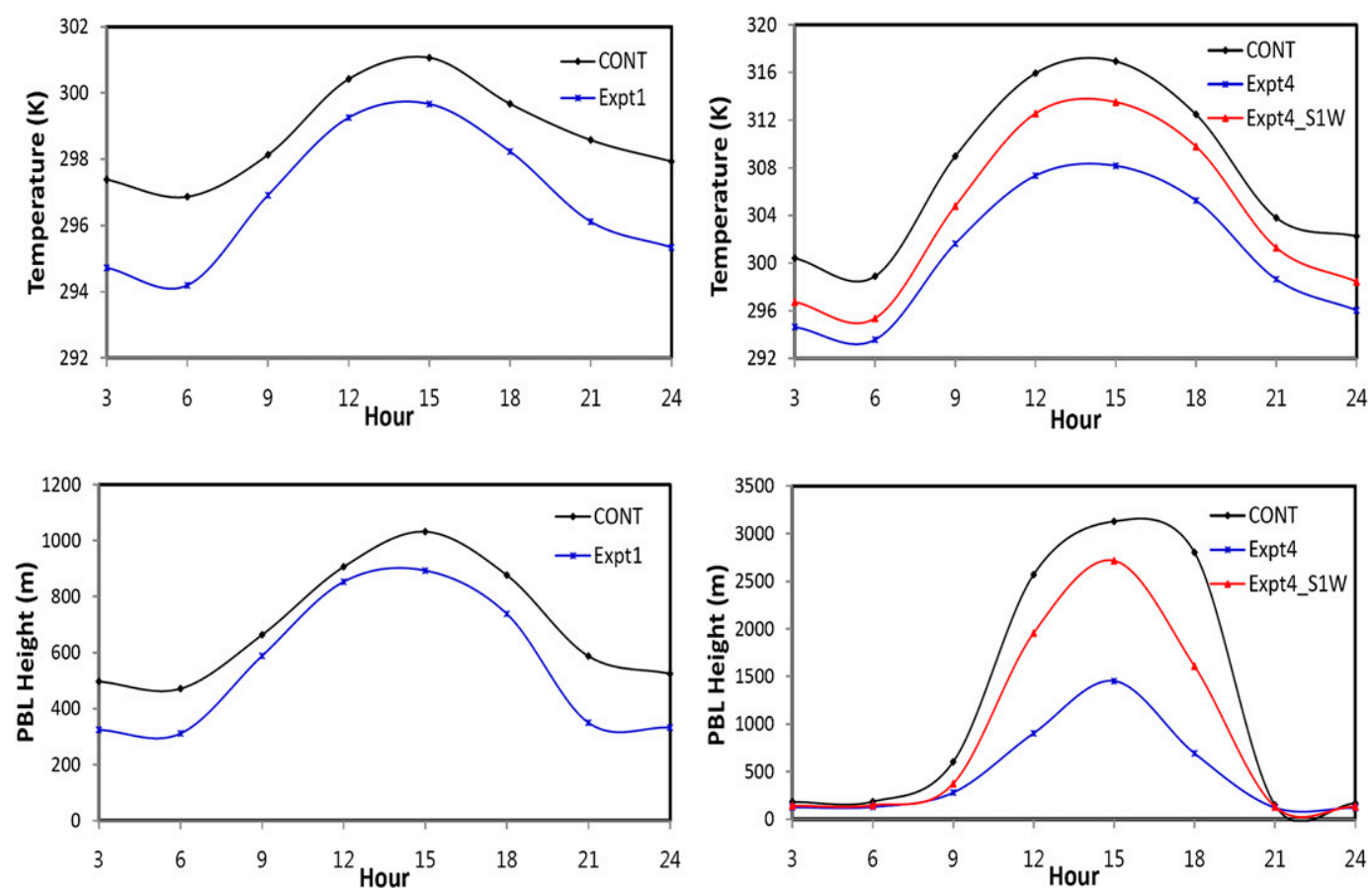

FIG. 5. Diurnal cycle of the (top) temperature and (bottom) PBL height averaged over irrigated area corresponding to each sensitivity experiments (Expt1 and Expt4).

in August when active convection is expected. While $\mathrm{CIN}$ indicates the negative buoyant energy barrier to be overcome for free ascent of an air parcel, the CAPE characterizes the positive buoyancy of a rising air parcel, which thus can be an indicator of atmospheric instability. The comparison of these indices between CONT and Expt4 shows that irrigation can significantly modulate the atmospheric thermodynamic structure, leading to enhancement or suppression of triggering convection. The wet soil moisture is expected to lead to the higher moist static energy (as described $\theta_{e}$ ) owing to the increase of the total flux of heat from the land surface, and

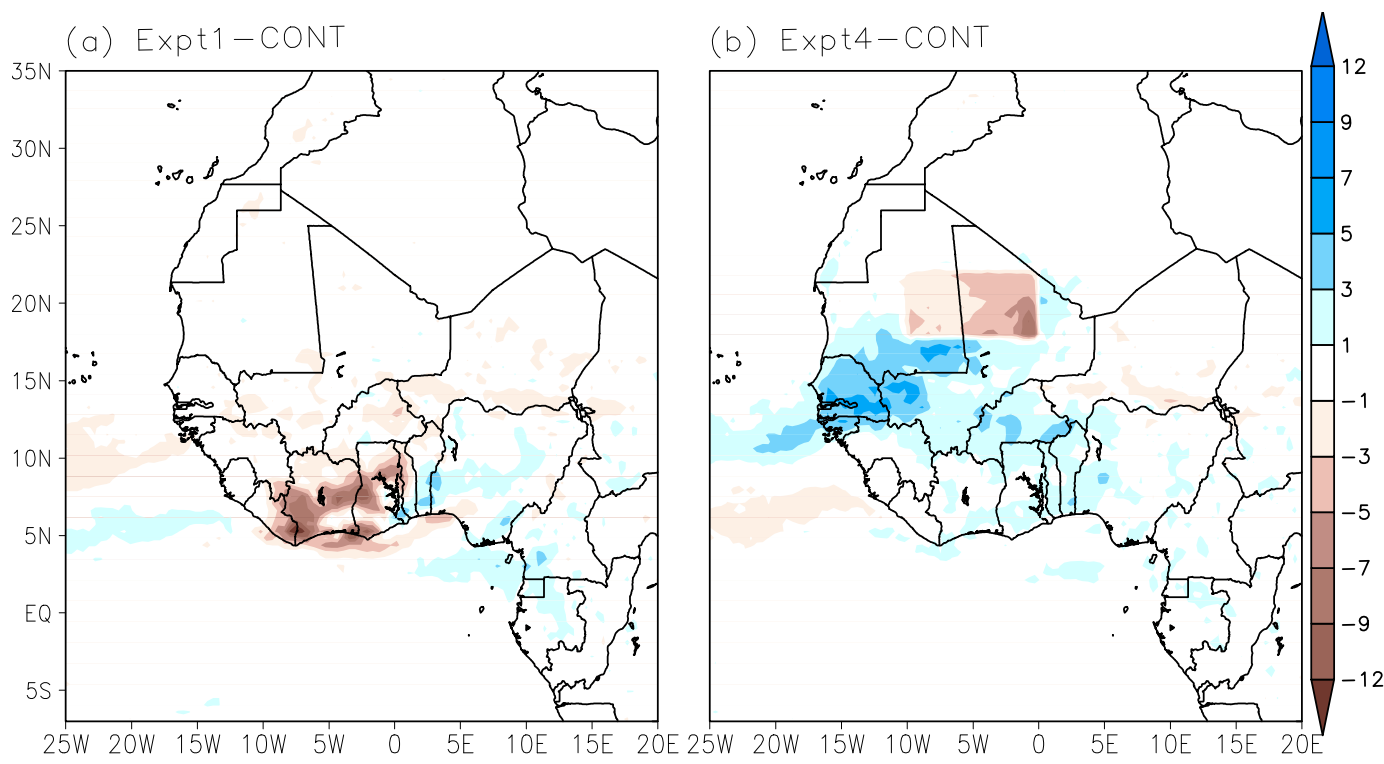

FIG. 6. The difference of number of days with convective rainfall greater than $1.0 \mathrm{~mm}^{-1}{ }^{-1}$ between (a) Expt 1 and (b) Expt4 and CONT experiment for August. 

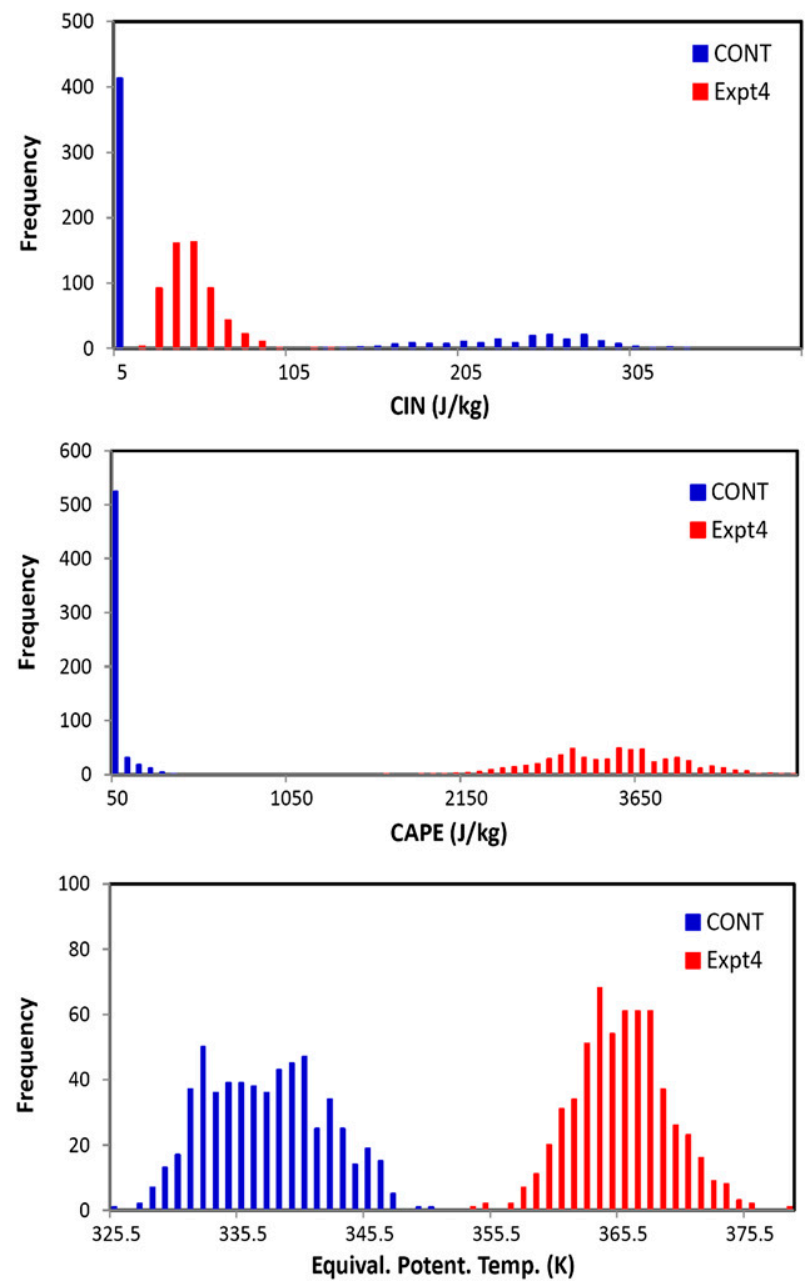

FIG. 7. Frequency distribution of (top) $\mathrm{CIN}\left(\mathrm{J} \mathrm{kg}^{-1}\right)$, (middle) CAPE $\left(\mathrm{J} \mathrm{kg}^{-1}\right)$, and (bottom) $\theta_{e}(\mathrm{~K})$ derived from the CONT and Expt4 experiments (averaged over $10^{\circ} \mathrm{W}-0^{\circ}$ and $18^{\circ}-22^{\circ} \mathrm{N}$ for Expt4 irrigated area) at 1200 UTC in August. Each histogram for CIN, CAPE, and $\theta_{e}$ has the interval of 10,100 , and 1 , respectively. For example, 5 in CIN distribution denotes the median value in the range from 0 to 10 .

this results in an increase of CAPE (Eltahir 1998; Findell and Eltahir 2003). Our results are in line with those findings, showing that the $\theta_{e}$ and CAPE derived from Expt 4 are significantly larger than the corresponding values in CONT.

Enhanced soil moisture simultaneously reduces PBL height owing to evaporative cooling as seen in Fig. 5. The simulated reduction of the PBL height tends to inhibit convective triggering. Indeed, in spite of the higher moist static energy and CAPE, Expt4 results are dominated by the enhanced inhibition of convective triggering. Expt 4 produces the maximum frequency of CIN between 40 and 50 values, whereas CIN values from CONT are mostly distributed in the range from 0 to 10 (more than $70 \%$ ). Therefore, the increase in convective available potential energy owing to higher surface moist static energy seems to be dominated and overwhelmed by the decrease in frequency of convective triggering owing to enhanced convective inhibition.

In addition, surface cooling due to the soil moisture forcing induces significant changes in low-level circulation. Figure 8 presents the difference in geopotential height and wind vector at $925 \mathrm{hPa}$ between Expt1 (Expt4) and the CONT simulation. Higher pressure centered at the irrigated area is associated with anomalous descending motion, leading to low-level divergence over the irrigated region. These low-level outflows result in anomalous anticyclonic circulation. In general, both Expt 1 and Expt4 produce a similar anomalous circulation, but with different magnitudes in response to different supplied irrigation water forcing. As will be shown in the next section, the remote effects of this circulation change appear to be more dominant in Expt4, whereas Expt 1 tends to be more dominated by the local effect as the cooling seen in Expt1 is not enough to further affect rainfall around the irrigated area.

\section{c. The mechanism of remote impact of irrigation on rainfall}

In section $3 \mathrm{~b}$, we demonstrate that surface cooling locally drives the rainfall decrease in the irrigated area; however, the circulation change induced by the reduction in rainfall can modulate the rainfall change at remote locations farther away from the irrigated land. For in-depth analysis of remotely controlled effects, we examine the dynamic interaction between monsoon flow and anomalous flows induced by irrigation on an intraseasonal time scale. Since the West African monsoon shows a marked intraseasonal variation, examining the characteristics of the changes in rainfall and circulation on a month by month basis could be helpful in understanding the wide range of responses that may result from varying the location of the irrigated area relative to the spatial pattern of the low-level monsoon wind. Although the average pattern for the period from May to September might provide the gross features of the interaction between irrigation and monsoon (e.g., Fig. 3), this analysis could conceal detailed characteristics of the underlying mechanism.

Figure 9 presents the monthly-mean rainfall of CONT averaged over the irrigated area corresponding to Expt3 and Expt4, as well as the supplied irrigation water and temperature change. Expt 3 and Expt 4 are selected for this comparison because they produce significant difference in rainfall patterns despite the relatively close locations of their irrigated areas. CONT produces a fairly different seasonal variation of rainfall over the Expt 3 and Expt 4 irrigated areas, reflecting different climatology for the two regions. Since the irrigated area 
(a) Expt1-CONT

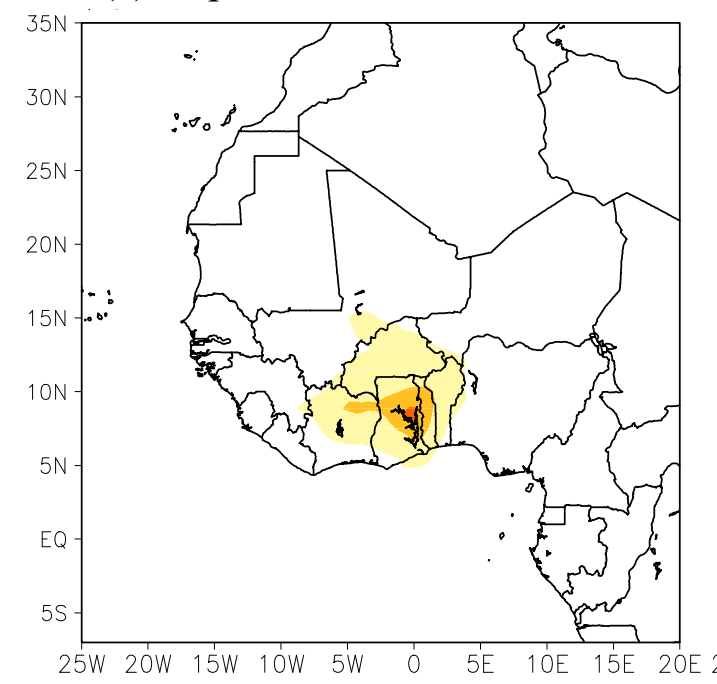

(c) Expt1-CONT

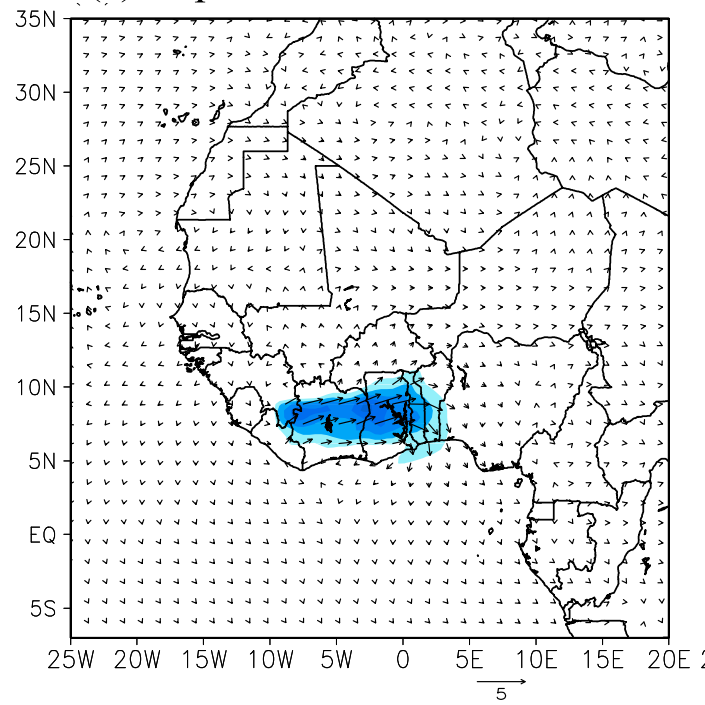

(b) Expt4-CONT

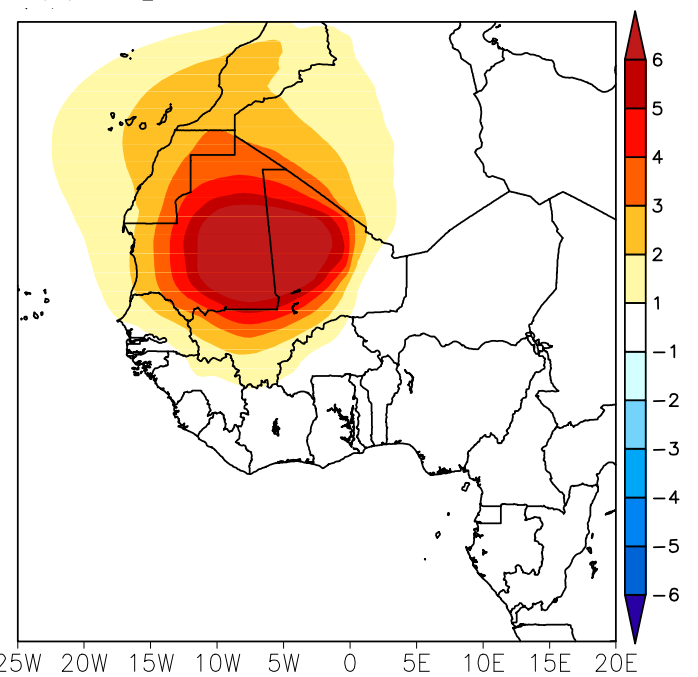

(d) Expt4-CONT

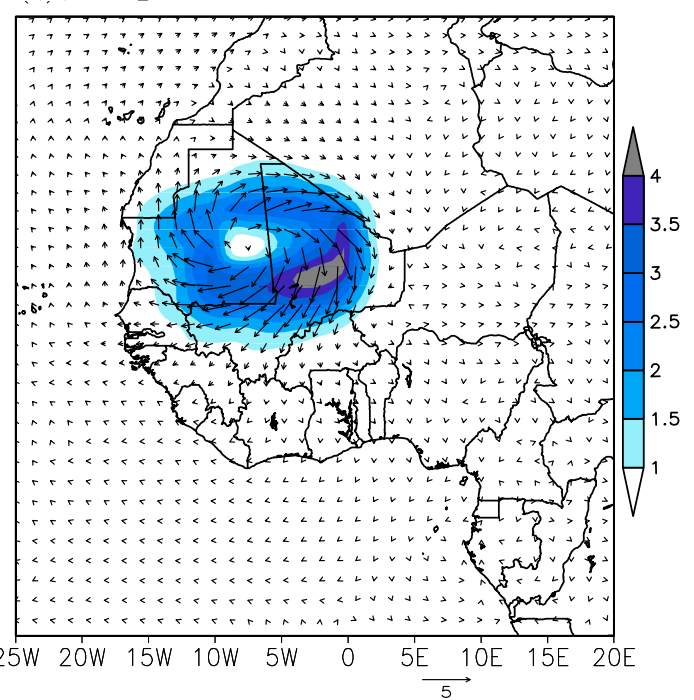

FIG. 8. Difference of the (top) geopotential height ( $\mathrm{m})$ and (bottom) wind vector $\left(\mathrm{m} \mathrm{s}^{-1}\right)$ at $925 \mathrm{hPa}$ between Expt1 (Expt4) and CONT simulation averaged over May to September. Color in wind difference indicates the magnitude of wind.

of Expt 3 is located in the northern Sahel, the amount of rainfall reaches up to $2.7 \mathrm{~mm} \mathrm{day}^{-1}$ in August as the West African monsoon progresses inland toward the Sahel region from the Guinean coast. However, the Expt4 irrigation is located even farther north, and its rainfall is much less than that of the Expt3 irrigation area. As a result, the two areas require a different amount of irrigation water. Once rainfall makes up part of the water needed to saturate the soil moisture, the amount of supplied water to assure sufficient soil moisture for irrigation is reduced in Expt3 relative to Expt4. As expected, the water required is inversely proportional to the rainfall. For example, applied water in Expt 3 is at its minimum in August when rainfall is at its highest. By comparison, Expt4 shows a similar amount of supplied water to Expt3 in May (Expt3: $71 \mathrm{~km}^{3}$ and Expt4: $68 \mathrm{~km}^{3}$ ), but the difference between the simulations becomes quite large by August (Expt3: $31 \mathrm{~km}^{3}$ and Expt4: $50 \mathrm{~km}^{3}$ ). The magnitudes of temperature decrease are directly related to the supplied irrigation water. Except for May, Expt4 produces consistently much lower temperature due to larger forcing of the supplied water. 

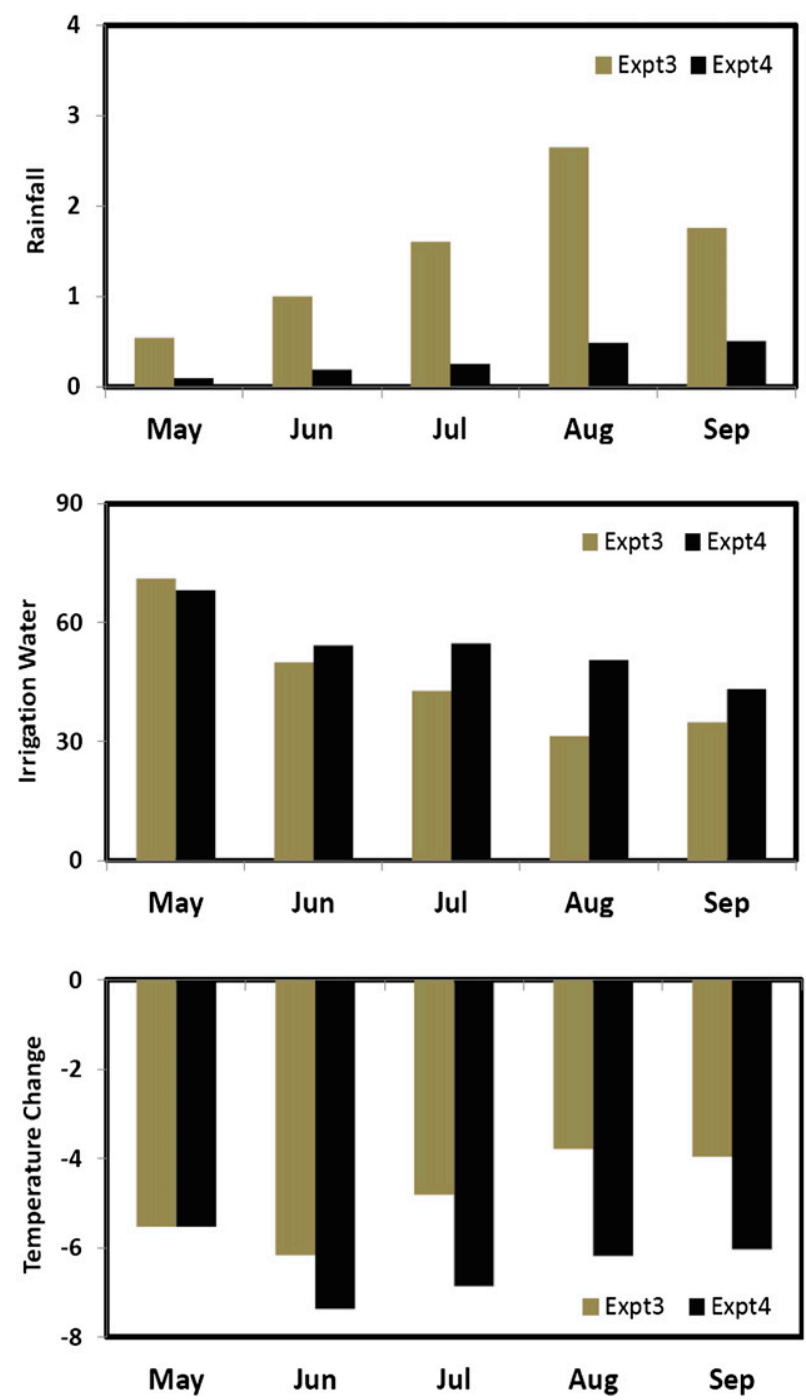

FIG. 9. Monthly variation (top) of rainfall $\left(\mathrm{mm} \mathrm{day}^{-1}\right)$ of the CONT simulation averaged over the Expt 3 and Expt 4 irrigated area and (middle) of supplied irrigation water $\left(\mathrm{km}^{3}\right)$ for Expt3 and Expt4; (bottom) temperature difference (K) between Expt3 and Expt 4 and CONT simulation averaged over the Expt3 and Expt4 irrigated area.

Figure 10 presents the spatial distribution of monthlymean rainfall differences between the Expt3 (Expt4) and CONT simulations from May to September. The figure shows that in Expt 3 the areas of increased rainfall are limited in extent and tend to diminish in July and August. In contrast, Expt4 produces more significant rainfall changes mainly to the southwest of the irrigated area from July to September.

The different patterns in monthly rainfall response are caused by the corresponding large-scale dynamics of the West African monsoon. Figure 11 presents the monsoon flows from the CONT simulation (black arrows), anomalous low-level flows induced by each sensitivity experiment (Expt3, Expt4, and Expt5: red arrows), and the resultant rainfall change (shading) together along the irrigated area $\left(10^{\circ} \mathrm{W}-0^{\circ}\right)$ on the monthly basis. This figure shows the proposed mechanism responsible for changes in rainfall through interaction between the prevailing monsoon flow and imposed anomalous flows owing to irrigation. Expt3, Expt4, and Expt5 all produce an anomalous anticyclonic circulation in the low level centered at the irrigated region because of excessive surface cooling. However, the different latitudinal location and magnitude of the anticyclonic circulation causes a marked difference in rainfall changes. The key determinants of the change of rainfall pattern is the timing and location of the northeasterly outflows derived from anticyclonic circulation. The northeasterly outflows collide with the prevailing (southwesterly) monsoonal flows causing additional convergence. Therefore, the optimal position and right timing of northeasterly outflows leads to a favorable condition for convergence consistent with the prevailing monsoon flow, its latitudinal dependence, and month to month variation.

For example, Expt3 does not simulate optimal timing of maximum wind converging with the prevailing monsoon flows. Expt3 produces the maximum wind in May and June because of the strong forcing of irrigation water during those months, as seen in Fig. 9, whereas the prevailing southwesterlies penetrating the Guinean coast and Soudano-Sahelian region become mature in July and August (more clearly seen in Figs. 12e,f). Therefore, this out of phase strengthening of low-level flows tends to be less effective in developing strong convergence. On the other hand, Expt5 illustrates the importance of the location of the irrigation-induced lowlevel flow. The northeasterly outflows produced by Expt5 are located too far north to converge with monsoon flows. In this regard, Expt4 is an optimal example for effective enhancement of the convergence zones between anomalous outflow and prevailing monsoonal winds, in both timing and location.

Figure 12 presents the meridional distribution of zonally averaged $\left(10^{\circ} \mathrm{W}-0^{\circ}\right)$ rainfall and wind magnitude from May to September, again emphasizing the importance of proper timing and location of anomalous outflows for increasing the rainfall. The wind magnitude from the CONT simulation (Fig. 12e) describes the characteristics of monsoon progress, reaching its peak in July and August across the Sahel region. Under this climatological condition, the maximum wind magnitude occurring in May and June (Expt3) as well as the anomalous wind located too far north (Expt5) are less effective in producing additional convergence, compared to Expt4. Therefore, the changes in rainfall show a large sensitivity in response to the latitudinal displacement of the irrigation area. 


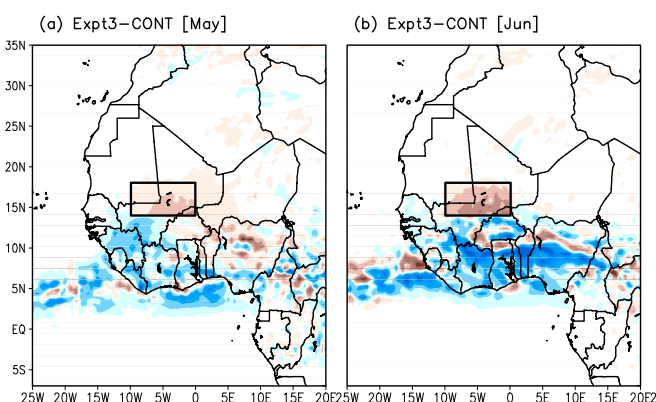

(c) Expt3-CONT [Jul]

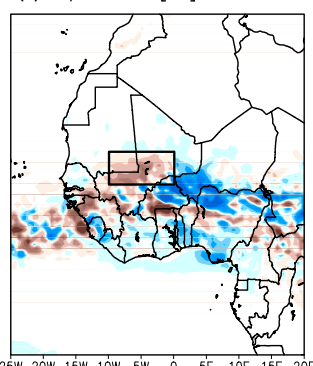

(d) Expt3-CONT [Aug]

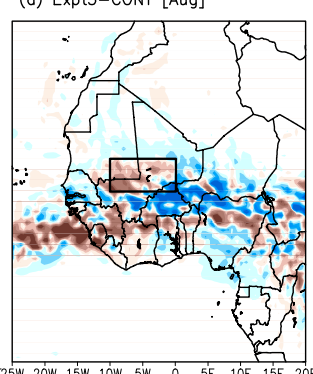

(e) Expt3-CONT [Sep]

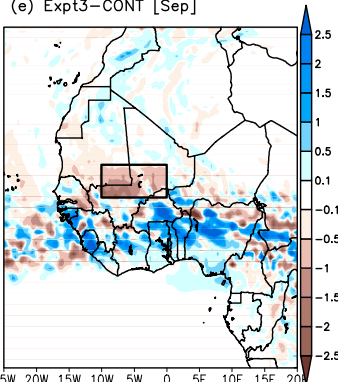

(f) Expt4-CONT [May]

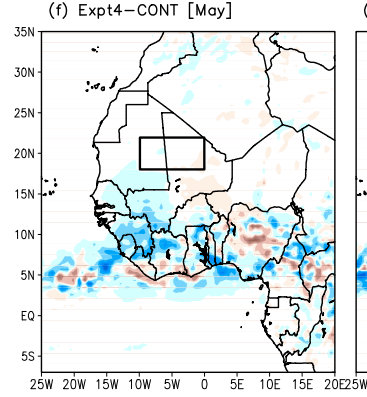

(g) Expt4-CONT [Jun]

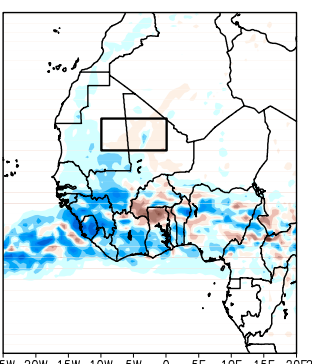

(h) Expt4-CONT [Jul]

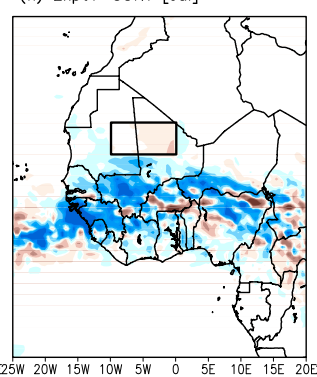

(i) Expt4-CONT [Aug]

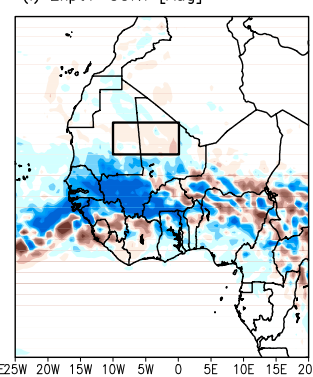

(j) Expt4-CONT [Sep]

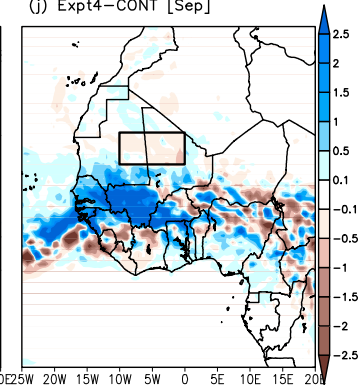

FIG. 10. Spatial distribution of monthly mean rainfall difference $\left(\mathrm{mm} \mathrm{day}^{-1}\right)$ between (top) Expt3 and (bottom) Expt4 and CONT simulation from May to September. The black line rectangle indicates the irrigated area for each sensitivity experiment.

\section{d. The effect of irrigation scheduling on rainfall change}

In this section, we examine the effect of irrigation scheduling to bring some realism into the design of the irrigation experiments. As described in Table 1, we perform an additional simulation allowing for irrigation scheduling to intermittently supply water imposed on Expt4, named Expt4_S1W.

Figure 13 presents the rainfall change derived from Expt4 and Expt4_S1W in the same format as in Fig. 3. As the scheduling technique is imposed, the supplied water is accordingly reduced. Consequently, the sensitivity of rainfall in response to irrigation is reduced. Based on Fig. 5 (red line in right panels), Expt4_S1W tends to reduce the magnitude of decrease in temperature and PBL height compared to those of Expt4. This follows suit to our previous findings. That is, compared to results without scheduling, this scheduling experiment tends to preserve the general pattern of rainfall change but with less magnitude because of reduced magnitude of the irrigation forcing.

To provide a more quantitative measure of the "water use efficiency," we define a simple index $\left(I_{\text {ratio }}\right)$ as the ratio between the accumulated change in rainfall volume over the whole domain and the supplied water for irrigation. Figure 14 presents a 20 -yr mean value of $I_{\text {ratio }}$ and the fraction of the simulation years with $I_{\text {ratio }}$ greater than one for all sensitivity experiments. An $I_{\text {ratio }}$ value above one indicates that irrigation potentially increases water availability since the water gained due to increase in rainfall is larger than the water required to irrigate. Figure 14 clearly demonstrates a large sensitivity and range of water efficiency values, suggesting the importance of optimizing irrigation returns based on irrigation location and scheduling. For example, with the values of Expt1 $\left(I_{\text {ratio }}=\right.$ -3.5) and Expt2 $\left(I_{\text {ratio }}=-1.0\right)$, the additional water needed for irrigation is not compensated enough by increases in rainfall; in terms of water balance, these cases are undesirable. In contrast, Expt $4\left(I_{\text {ratio }}=1.5\right)$ and Expt6 $\left(I_{\text {ratio }}=1.2\right)$ simulate rainfall that exceeds the supplied water for irrigation; in these cases, the assumed irrigation is favorable. Interestingly, when applying irrigation scheduling, the efficiency of water use is enhanced. Expt4_S1W $\left(I_{\text {ratio }}=1.9\right)$ provides an increased ratio compared to that of Expt4 $\left(I_{\text {ratio }}=1.5\right)$. Therefore, this scheduling technique seems to be more efficient at water recycling at the local and regional scale. More specifically, although the additional rainfall amount produced by Expt4_S1W $\left(172 \mathrm{~km}^{3} /\right.$ MJJAS $)$ is significantly smaller than that of Expt4 $\left(407 \mathrm{~km}^{3} / \mathrm{MJJAS}\right)$; the supplied water $\left(92 \mathrm{~km}^{3} /\right.$ MJJAS) is remarkably less than that of Expt4 $\left(271 \mathrm{~km}^{3} /\right.$ MJJAS). Therefore, the ratio could increase in scheduling experiments, indicating higher efficiency of water use. Based on the comparison of the sensitivity experiments in this study, the latitudinal location of irrigation is the most critical factor in determining the changes in the rainfall distribution due to irrigation. Ultimately, the proper scheduling of irrigation could help to enhance the efficiency of water use in a region that is water stressed. 

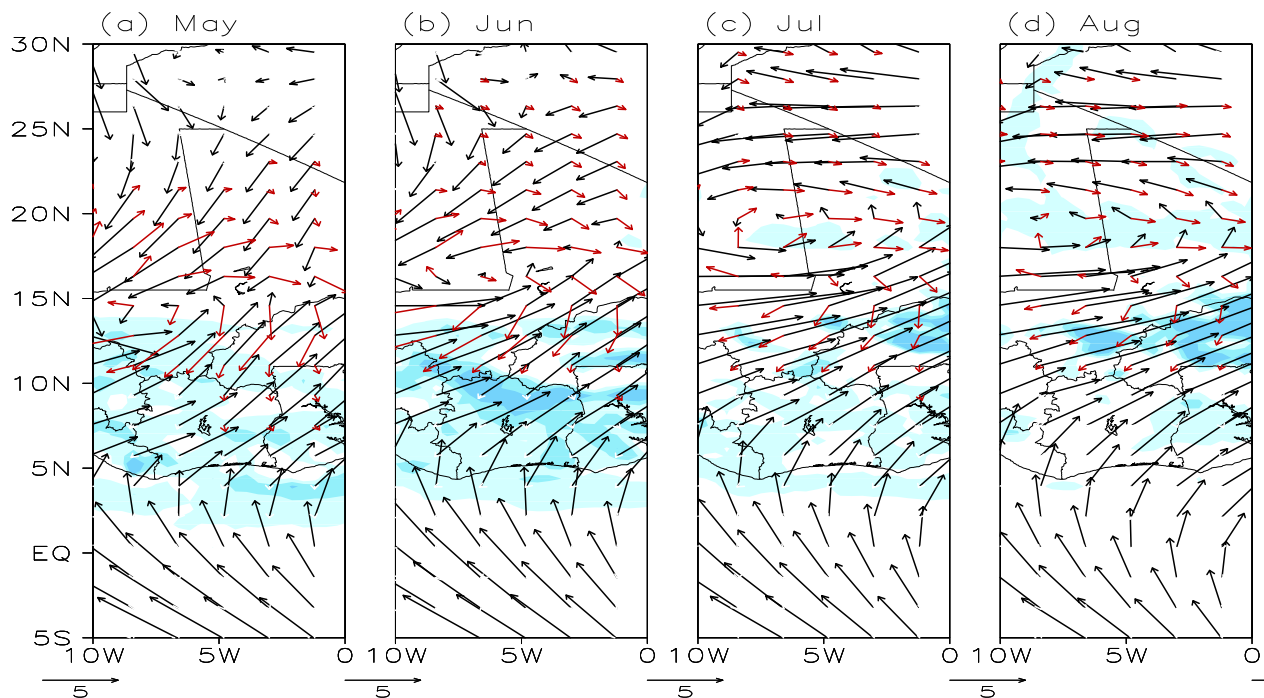

(e) Sep
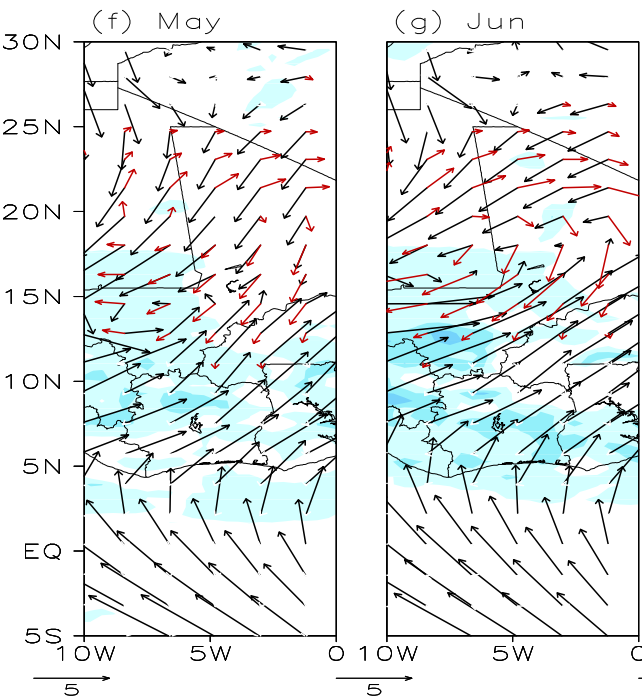

(h) Jul

(i) Aug
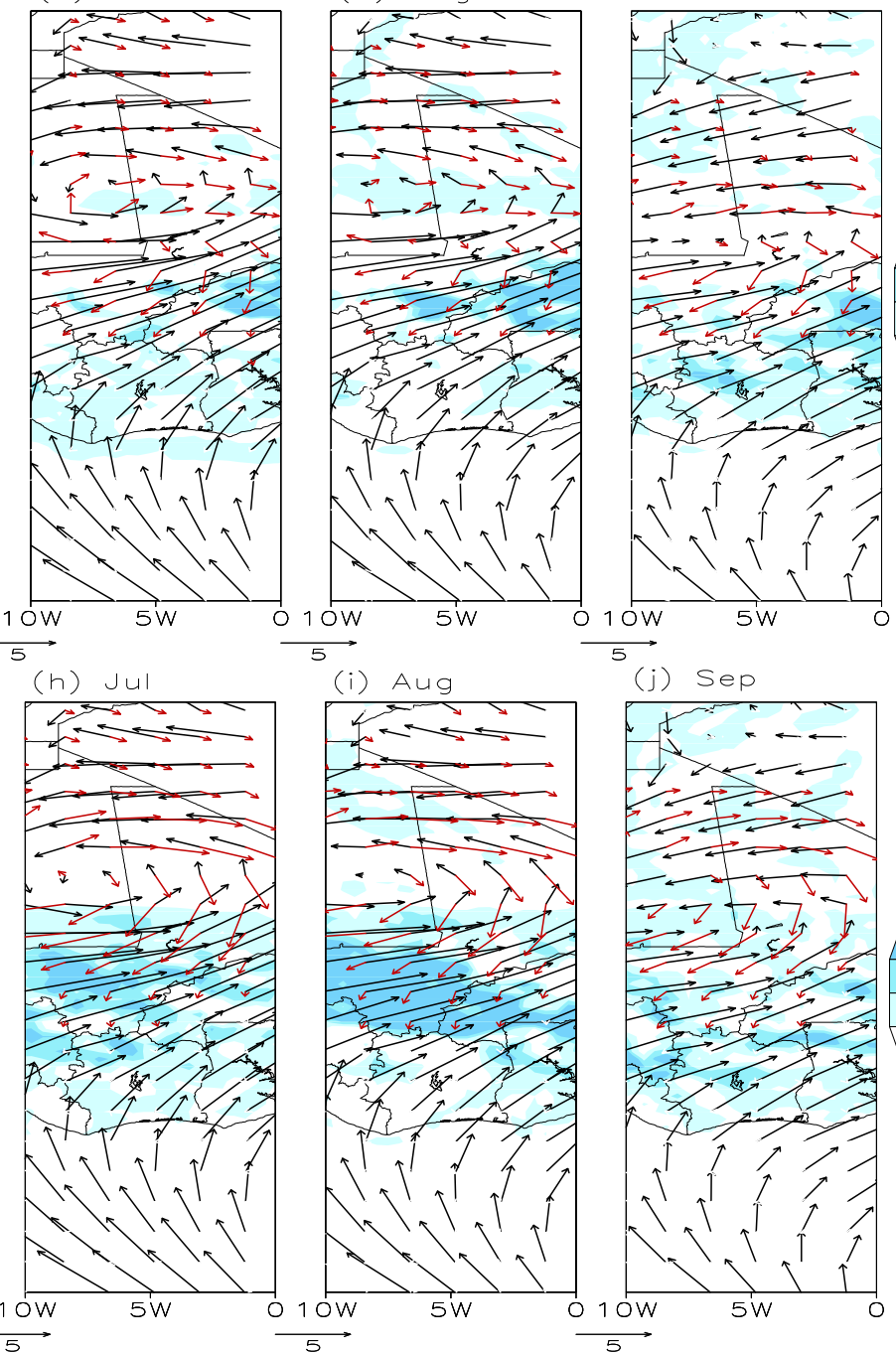

(j) Sep
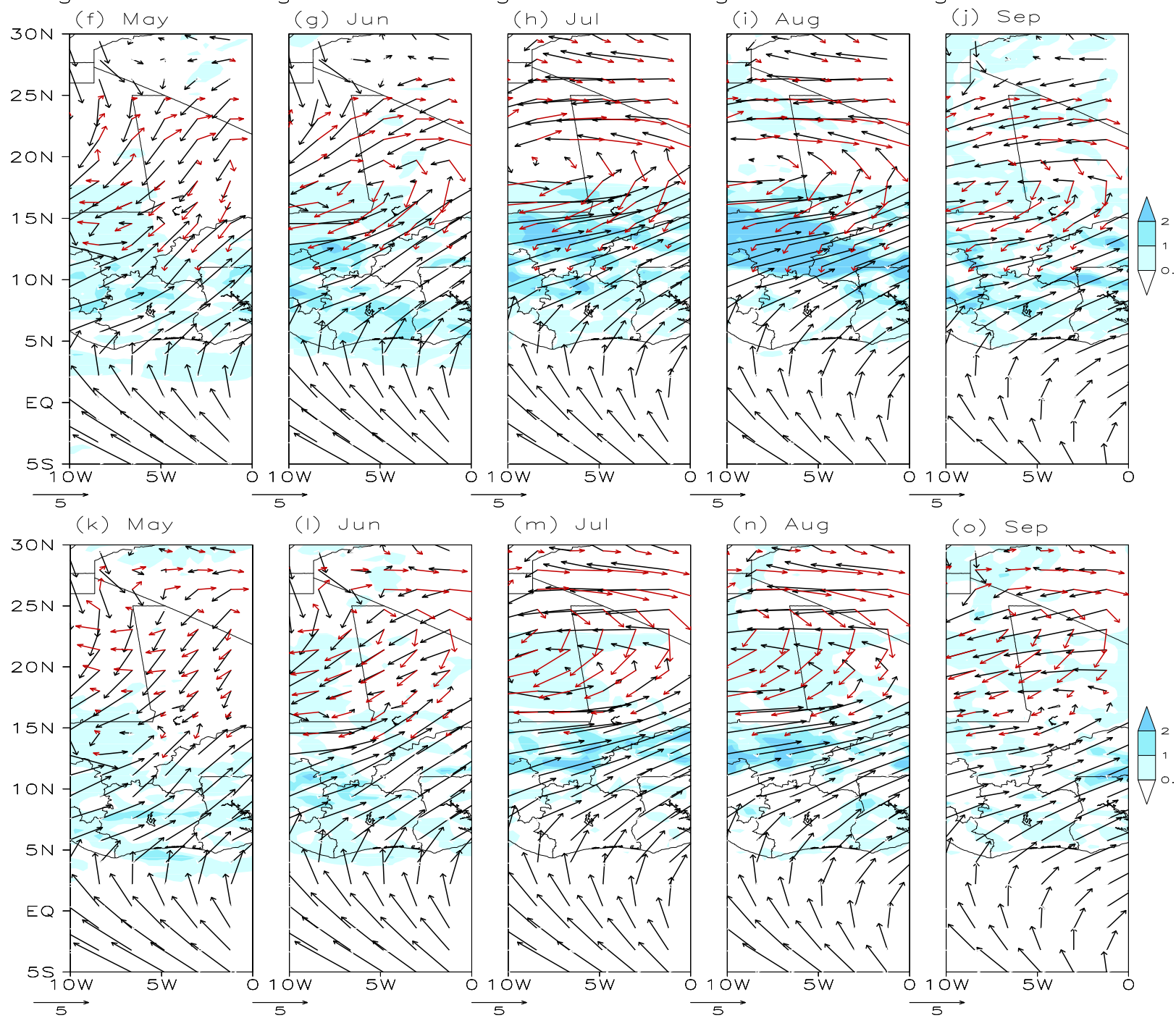

FIG. 11. Spatial distribution of monthly mean rainfall difference (shading) and wind difference at $925 \mathrm{hPa}$ (red arrows) between (top) Expt 3, (middle) Expt4, and (bottom) Expt5 and CONT simulation from May to September. Black arrows in all panels are climatology wind vector from CONT simulation and the upper, middle, and lower panels are the same. Shading areas in Expt3 and Expt4 are the same as the areas in rainfall increase of Fig. 10. 

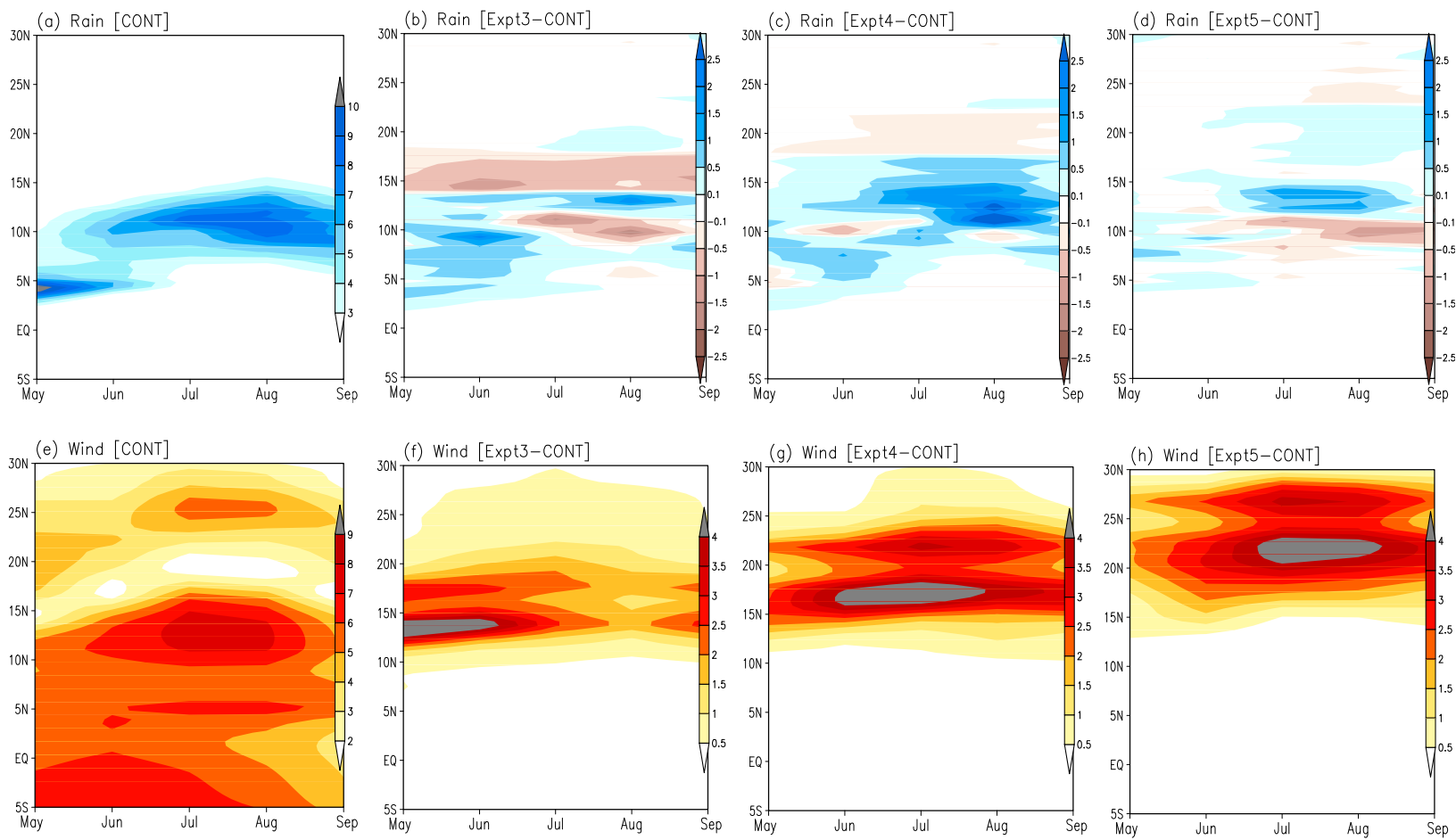

FIG. 12. Latitude-time cross section of (a) monthly mean rainfall and (e) wind magnitude averaged from $10^{\circ} \mathrm{W}$ to $0^{\circ}$ from the CONT simulation and their difference with (b),(f) Expt3, (c),(g) Expt4, and (d),(h) Expt5.

\section{Summary and conclusions}

To estimate the potential impact of irrigation on the West African monsoon, we analyze a suite of regional climate model experiments. Using the MIT regional climate model (MRCM) and its new scheme for irrigation

(a) Expt4-CONT

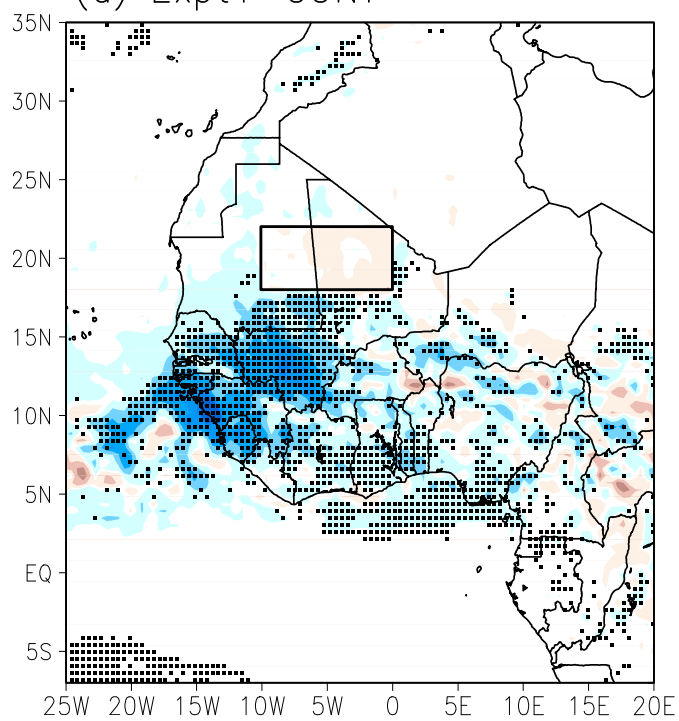

incorporated into the Integrated Biosphere Simulator (IBIS), the sensitivity analysis includes a control simulation with no irrigation and eight simulations varying scenarios of irrigation over West Africa. These simulations are designed to isolate the effect of irrigation location and scheduling on rainfall over the region.

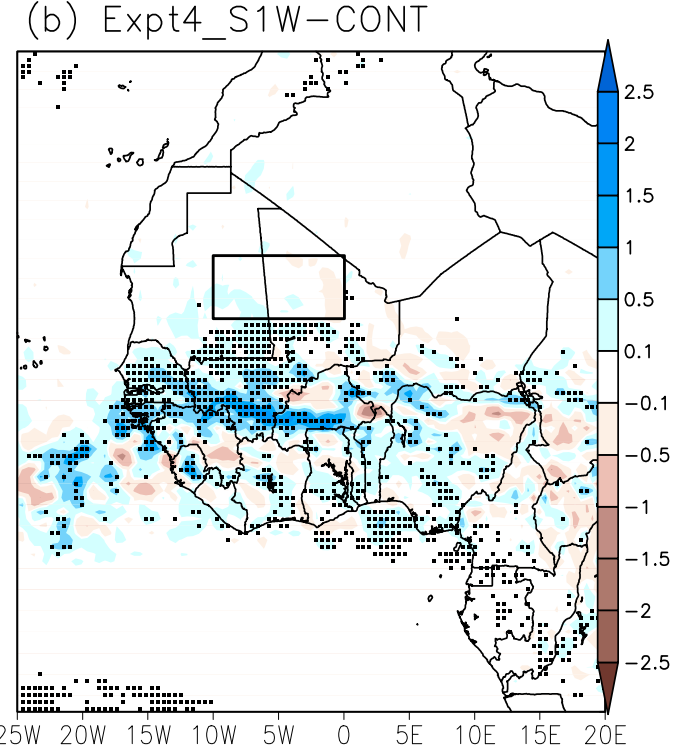

FIG. 13. As in Fig. 3 but for Expt4 and Expt4_S1W. Expt4 is the same as the one presented in Fig. 3. 


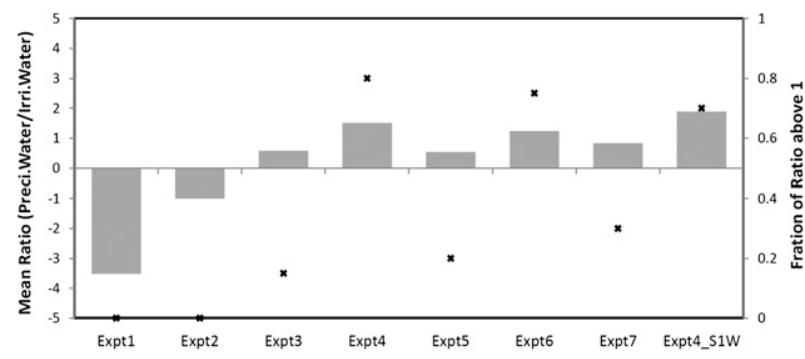

FIG. 14. The bar indicates the ratio between accumulated rainfall volume difference (sensitivity experiments minus CONT) over the whole domain and the amount of applied water for each irrigation sensitivity experiments during MJJAS. The cross mark indicates the fraction of the year with the ratio greater than 1 .

Figure 15 schematically summarizes the proposed mechanism on how wet soil moisture due to irrigation can modulate the rainfall changes both locally and remotely. The local effect induced by strong surface cooling tends to decrease the rainfall over the irrigated fields itself. In spite of enhanced moist static energy and resultant higher CAPE, a significant increase in convective inhibition dominates and hinders the triggering of convection. This effect is independent of the location of the irrigation area.

In contrast, the remote effect of irrigation on rainfall distribution shows a large sensitivity of rainfall change over the Guinean coast and Sahel region. The determinant is the geographical location of northeasterly outflows corresponding to an anticyclonic circulation induced by the anomalous descending motion over the irrigated area. In terms of irrigation location effects, our results indicate rainfall increases owing to the convergence between the existing monsoonal flow and anomalous low-level anticyclonic flows. It is important to note that complex and nonlinear responses are involved in regulating the West African monsoon circulation and resultant rainfall changes. However, we suggest that the position and timing of anomalous northeasterly flow corresponding to the anticyclonic circulation affects the extent of low-level convergence areas through interaction with prevailing monsoonal flows. As the location of the irrigation area is moved from the coast northward, the regional rainfall change exhibits a significant decrease first, then increases gradually to a maximum corresponding to irrigation centered around $20^{\circ} \mathrm{N}$, before it declines again. Our results demonstrate a larger sensitivity to latitudinal position, rather than longitudinal position, of the irrigated area. Last, a scheduling method to intermittently supply irrigation water enhances the efficiency of water use through the reduction of supplied irrigation water but still significant enhancement of rainfall distribution.

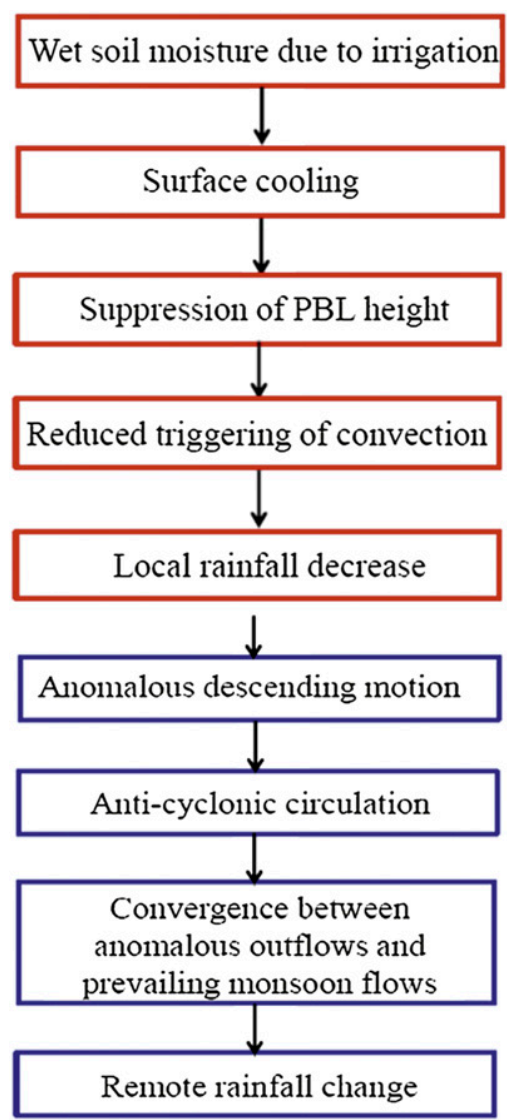

FIG. 15. Schematic diagram of local (red outline) and remote (blue outline) effects leading to rainfall changes in the irrigation experiments.

If irrigation can be shown to enhance rainfall over the Sahel, that conclusion would have important implications to many countries in West Africa. In general, we conclude that an additional supply of irrigation water does not necessarily induce a proportional increase in rainfall. Our results indicate that an optimal irrigation location and scheduling exists that should lead to the most efficient use of irrigation water.

One possible caveat to note is that any regional climate model simulation is constrained by large-scale lateral boundary conditions (e.g., ERA-Interim reanalysis in this study), and hence the changes of energy and water budget presented in this study may not represent the full effects of model dynamics attributed to the irrigation forcing. In this regard, the simulations using the global climate model might reveal important aspects of the climatic impact of irrigation in Africa.

The simplistic and conceptually idealized experiments presented in this study suffer significant limitations in terms of the volume of irrigated water that is unrealistically large. We are not suggesting that our results at 
this stage have direct relevance to real world applications. Therefore, future work will consider more realistic designs for irrigation experiments by considering irrigation applied to smaller areas, as well as using different scheduling techniques. Working toward a more firm understanding of the potential impact of irrigation on the regional climate and its physical mechanism, a follow-up paper will focus on more realistic ways for enhancing regional water use efficiency through various irrigation designs. The ultimate goal is to gain further insight into the potential role of irrigation in shaping rainfall patterns over West Africa.

West Africa is a region that is vulnerable to droughts and is a hot spot for land-atmosphere interactions and their impact on climate. On the theoretical side, this paper highlights the sensitivity of induced land-atmosphere interactions in West Africa to the location and timing of the perturbations in land surface condition. On the practical side, if our findings are verified by further analysis assuming more realistic scenarios of irrigation, they could have important implications for optimal irrigation planning in Africa.

Acknowledgments. Funding for this study was provided by the Singapore National Research Foundation through the Singapore-MIT Alliance for Research and Technology (SMART), Center for Environmental Sensing and Modeling (CENSAM). The authors are grateful to two anonymous reviewers for the valuable feedback and suggestions that improved the manuscript.

\section{REFERENCES}

Adegoke, J. O., R. A. Pielke Sr., J. Eastman, R. Mahmood, and K. G. Hubbard, 2003: Impact of irrigation on midsummer surface fluxes and temperature under dry synoptic conditions: A regional atmospheric model study of the U.S. high plains. Mon. Wea. Rev., 131, 556-564.

Cook, B. I., M. J. Puma, and N. Y. Krakauer, 2011: Irrigation induced surface cooling in the context of modern and increased greenhouse gas forcing. Climate Dyn., 37, 1587-1600.

DeAngelis, A., F. Dominguez, Y. Fan, A. Robock, M. D. Kustu, and D. Robinson, 2010: Evidence of enhanced precipitation due to irrigation over the Great Plains of the United States. J. Geophys. Res., 115, D15115, doi:10.1029/2010JD013892.

Diffenbaugh, N. S., 2009: Influence of modern land over on the climate of the United States. Climate Dyn., 33, 945-958.

Eltahir, E. A. B., 1998: A soil moisture-rainfall feedback mechanism. 1. Theory and observations. Water Resour. Res., 34, 765-776.

Findell, K. L., and E. A. B. Eltahir, 2003: Atmospheric controls on soil moisture-boundary layer interactions. Part I: Framework development. J. Hydrometeor., 4, 552-569.

Gianotti, R. L., 2012: Regional climate modeling over the Maritime Continent: Convective cloud and rainfall processes. Ph.D. dissertation, Massachusetts Institute of Technology, $306 \mathrm{pp}$.
— , and E. A. B. Eltahir, 2014a: Regional climate modeling over the Maritime Continent. Part I: New parameterization for convective cloud fraction. J. Climate, in press.

- , and $-2014 \mathrm{~b}$ : Regional climate modeling over the Maritime Continent. Part II: New parameterization for autoconversion of convective rainfall. J. Climate, in press.

Koster, R. D., and Coauthors, 2004: Regions of strong coupling between soil moisture and precipitation. Science, 305, 1138-1140.

Kueppers, L. M., M. A. Snyder, and L. C. Sloan, 2007: Irrigation cooling effect: Regional climate forcing by land-use change. Geophys. Res. Lett., 34, L03703, doi:10.1029/2006GL028679.

Kustu, M. D., Y. Fan, and A. Robock, 2010: Large-scale water cycle perturbation due to irrigation pumping in the US high plains: A synthesis of observed streamflow changes. J. Hydrol., 390, 222-244.

,-- , and — 2011: Possible link between irrigation in the U.S. high plains and increased summer streamflow in the Midwest. Water Resour. Res., 47, W03522, doi:10.1029/ 2010WR010046.

Lo, M.-H., and J. S. Famiglietti, 2013: Irrigation in California's Central Valley strengthens the southwestern U.S. water cycle. Geophys. Res. Lett., 40, 301-306, doi:10.1002/GRL.50108.

Lobell, D., G. Bala, A. Mirin, T. Phillips, R. Maxwell, and D. Rotman, 2009: Regional differences in the influence of irrigation on climate. J. Climate, 22, 2248-2255.

Marcella, M. P., 2012: Biosphere-atmosphere interactions over semi-arid regions: Modeling the role of mineral aerosols and irrigation in the regional climate system. Ph.D. dissertation, Massachusetts Institute of Technology, $282 \mathrm{pp}$.

_ , and E. A. B. Eltahir, 2012: Modeling the summertime climate of southwest Asia: The role of land surface processes in shaping the climate of semiarid regions. J. Climate, 25, 704-719.

$\longrightarrow$, and - 2014: Introducing an irrigation scheme to a regional climate model: A case study over West Africa. J. Climate, in press.

Mohmood, R., and K. G. Hubbard, 2002: Anthropogenic land-use change in the North American tall grass-short grass transition and modification of near-surface hydrologic cycle. Climate Res., 21, 83-90.

Moore, N., and S. Rojstaczer, 2001: Irrigation-induced rainfall and the Great Plains. J. Appl. Meteor., 40, 1297-1309.

Nikulin, G., and Coauthors, 2012: Precipitation climatology in an ensemble of CORDEX-Africa regional climate simulations. J. Climate, 25, 6057-6078.

Ozdogan, M., M. Rodell, H. K. Beaudoing, and D. L. Toll, 2010: Simulating the effects of irrigation over the United States in a land surface model based on satellite-derived agricultural data. J. Hydrometeor., 11, 171-184.

Pal, J. S., and E. A. B. Eltahir, 2001: Pathways relating soil moisture conditions to future summer rainfall within a model of the land-atmosphere system. J. Climate, 14, 1227-1242.

—, and —, 2003: A feedback mechanism between soilmoisture distribution and storm tracks. Quart. J. Roy. Meteor. Soc., 129, 2279-2297.

- and Coauthors, 2007: The ICTP RegCM3 and RegCNET: Regional climate modeling for the developing world. Bull. Amer. Meteor. Soc., 88, 1395-1409.

Pielke, R. A., G. Marland, R. A. Betts, T. N. Chase, J. L. Eastman, J. O. Niles, D. D. S. Niyogi, and S. W. Running, 2002: The influence of land-use change and landscape dynamics on the climate system: Relevance to climate-change policy beyond the radiative effect of greenhouse gases. Philos. Trans. Roy. Soc. London, B360, 1705-1719. 
Segal, M., Z. Pan, R. W. Turner, and E. S. Takle, 1998: On the potential impact of irrigated areas in North America on summer rainfall caused by large-scale system. J. Appl. Meteor., 37, 325-331.

Sorooshian, S., J. Li, K. Hus, and X. Gao, 2011: How significant is the impact of irrigation on the local hydroclimate in California's Central Valley? Comparison of model results with ground and remote-sensing data. J. Geophys. Res., 116, D06102, doi:10.1029/2010JD014775.

,,$-- \ldots$, and -2012 : Influence of irrigation schemes used in regional climate models on evapotranspiration estimation: Results and comparative studies from California's Central Valley agricultural regions. J. Geophys. Res., 117, D06107, doi:10.1029/2011JD016978.
UNEP, 2011: Livelihood security: Climate change, migration and conflict in the Sahel. United Nations Environment Programme Rep., 108 pp.

Uppala, S., D. Dee, S. Kobayashi, P. Berrisford, and A. Simmons, 2008: Towards a climate data assimilation system: Status update of ERA-Interim. ECMWF Newsletter, No. 115, ECMWF, Reading, United Kingdom, 12-18.

Wang, G., Y. Kim, and D. Wang, 2007: Quantifying the strength of soil moisture-precipitation coupling and its sensitivity to changes in surface water budget. J. Hydrometeor., 8, $551-570$.

Winter, J. M., J. S. Pal, and E. A. B. Eltahir, 2009: Coupling of integrated biosphere simulator to regional climate model version 3. J. Climate, 22, 2743-2756. 